NUREG/CR-6351

CNWRA 94-002

\title{
Review of Scenario Selection
}

Approaches for Performance

Assessment of High-Level Waste

Repositories and Related Issues

Manuscript Completed: May 1995

Date Published: August 1995

Prepared by

E. J. Bonano, ${ }^{*}$ R. G. Baca

Southwest Research Institute

Center for Nuclear Waste Regulatory Analyses

6220 Culebra Road

San Antonio, TX 78228-0510

\section{Prepared for}

Division of Regulatory Applications

Office of Nuclear Regulatory Research

U.S. Nuclear Regulatory Commission

Washington, DC 20555-0001

NRC Job Code B6666 



\section{DISCLAIMER}

This report was prepared as an account of work sponsored by an agency of the United States Government. Neither the United States Government nor any agency thereof, nor any of their employees, make any warranty, express or implied, or assumes any legal liability or responsibility for the accuracy, completeness, or usefulness of any information, apparatus, product, or process disclosed, or represents that its use would not infringe privately owned rights. Reference herein to any specific commercial product, process, or service by trade name, trademark, manufacturer, or otherwise does not necessarily constitute or imply its endorsement, recommendation, or favoring by the United States Government or any agency thereof. The views and opinions of authors expressed herein do not necessarily state or reflect those of the United States Government or any agency thereof. 


\section{DISCLAIMER}

Portions of this document may be illegible in electronic image products. Images are produced from the best available original document. 


\begin{abstract}
The selection of scenarios representing plausible realizations of the future conditions-with associated probabilities of occurrence-that can affect the long-term performance of a high-level radioactive wante (HLW) repository is the commonly used method for treating the uncertainty in the prediction of the future states of the system. This method, conventionally referred to as the "scenario approach," while common is not the only method to deal with this uncertainty; other methods, such as the environmental simulation approach (ESA), have also been proposed. Two of the difficulties with the scenario approach are the lack of uniqueness in the definition of the term "scenario" and the lack of uniqueness in the approach to formulate scenarios, which relies considerably on subjective judgments. Consequently, it is difficult to assure that a complete and unique set of scenarios can be defined for use in a performance assessment. Because scenarios are key to the determination of the long-term performance of the repository system, this lack of uniqueness can present a considerable challenge when attempting to reconcile the set of scenarios, and their level of detail, obtained using different approaches, particularly among proponents and regulators of a HLW repository.

In this report we document a review of scenario selection approaches being used by the major radioactive waste management program participants in the United States and in several countries of the Organization of Economic Cooperation and Development. Because it has been proposed as an alternative to the scenario approach to overcome the latter's limitations, for the sake of completeness, the ESA is also reviewed. The review attempts to highlight the similarities and differences between the different approaches. The report concludes with a brief discussion of key issues related to scenario selection that remain open and warrant attention.
\end{abstract}





\section{CONTENTS}

Section

Page

FIGURES $\ldots \ldots \ldots \ldots \ldots \ldots \ldots \ldots \ldots \ldots \ldots \ldots \ldots \ldots \ldots \ldots \ldots \ldots$ vii

TABLES $\ldots \ldots \ldots \ldots \ldots \ldots \ldots \ldots \ldots \ldots \ldots \ldots \ldots \ldots \ldots \ldots \ldots \ldots \ldots \ldots$

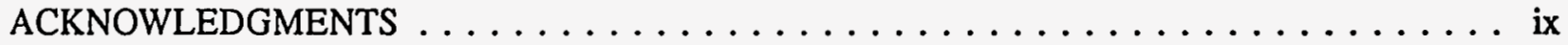

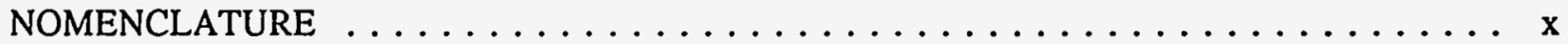

$1 \quad$ INTRODUCTION $\ldots \ldots \ldots \ldots \ldots \ldots \ldots \ldots \ldots \ldots \ldots \ldots \ldots \ldots \ldots$

1.1 PURPOSE AND SCOPE OF REPORT $\ldots \ldots \ldots \ldots \ldots \ldots \ldots \ldots \ldots$

1.2 SCENARIOS AND UNCERTAINTY IN THE FUTURE

STATES OF THE DISPOSAL SYSTEM $\ldots \ldots \ldots \ldots \ldots \ldots \ldots \ldots \ldots \ldots \ldots$

$1.3 \quad$ ORGANIZATION OF REPORT $\ldots \ldots \ldots \ldots \ldots \ldots \ldots \ldots \ldots \ldots$

2 SCENARIO SELECTION APPROACHES IN THE UNITED STATES . . . . . . . 2-1

2.1 SCENARIO APPROACHES USED BY THE NUCLEAR REGULATORY COMMISSION .......................... 2-1

2.1.1 Scenario Methodology by Sandia National Laboratories . . . . . . . . . . . . . . . 2-1

2.1.2 Scenario Approach for Iterative Performance Assessment Exercises . . . . . . . . . 2-5

2.2 SCENARIO APPROACH ADOPTED BY THE U.S. DEPARTMENT OF

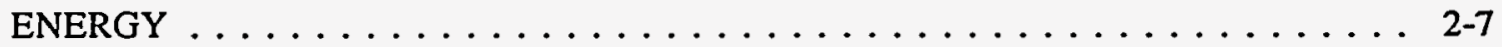

2.2 .1 Yucca Mountain Project . . . . . . . . . . . . . . . . . . 2-8

2.2 .2 Waste Isolation Pilot Plant Project . . . . . . . . . . . . . . . . 2-12

2.3 SCENARIO ANALYSIS IN ELECTRIC POWER RESEARCH INSTITUTE STUDIES . . . . . . . . . . . . . . . . . . . . . 2-17

3 SCENARIO SELECTION APPROACHES IN THE ORGANIZATION FOR ECONOMIC COOPERATION AND DEVELOPMENT COUNTRIES . . . . . . . . 3-1

3.1 CANADIAN SCENARIO SELECTION APPROACH $\ldots \ldots \ldots \ldots \ldots \ldots \ldots$

3.2 SWEDISH SCENARIO SELECTION APPROACH $\ldots \ldots \ldots \ldots \ldots \ldots \ldots \ldots \ldots$

3.3 UK NireX Ltd. SCENARIO SELECTION APPROACH $\ldots \ldots \ldots \ldots \ldots \ldots \ldots \ldots$

$3.4 \quad$ SCENARIO SELECTION APPROACH IN FRANCE $\ldots \ldots \ldots \ldots \ldots \ldots \ldots$

4 ENVIRONMENTAL SIMULATION APPROACH $\ldots \ldots \ldots \ldots \ldots \ldots \ldots$

4.1 UNITED KINGDOM DEPARTMENT OF ENVIRONMENT'S ENVIRONMENTAL

SIMULATION APPROACH $\ldots \ldots \ldots \ldots \ldots \ldots \ldots \ldots \ldots \ldots \ldots \ldots$. . . . . .

5 OPEN ISSUES IN SCENARIO SELECTION $\ldots \ldots \ldots \ldots \ldots \ldots \ldots \ldots \ldots$

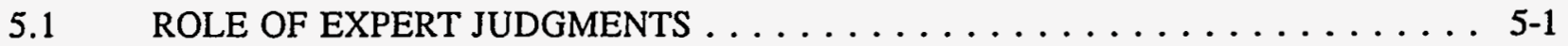

5.1.1 Expert Judgment Elicitation for Human Intrusion into the Waste Isolation Pilot

Plant . . . . . . . . . . . . . . . . . . . . . . 5 5-2

5.1.2 Expert Judgment Elicitation for Future Climate at Yucca Mountain . . . . . . . . 5 5-6 


\section{CONTENTS (Cont'd)}

Section

Page

5.1 .3 Other Expert Judgment Issues $\ldots \ldots \ldots \ldots \ldots \ldots \ldots \ldots \ldots \ldots$

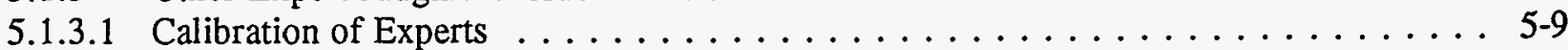

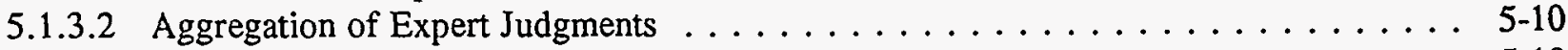

5.1 .3 .3 Level of Rigor in Expert Elicitation . . . . . . . . . . . . . . . . . 5-10

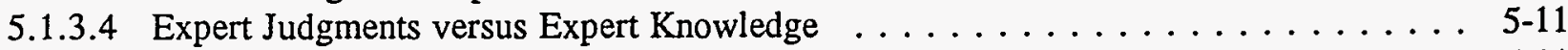

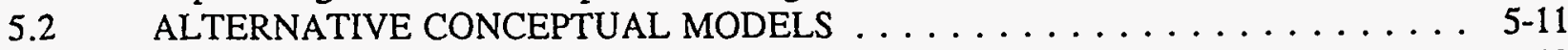

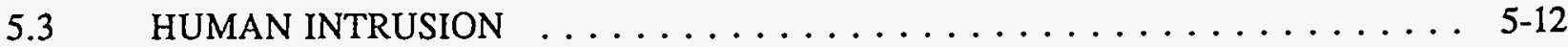

5.3.1 Nuclear Energy Agency Human Intrusion Workshop . . . . . . . . . . . . . . . 5-13

$5.4 \quad$ OTHER IMPORTANT ISSUES . . . . . . . . . . . . . . . . $5-14$

5.4 .1 Lack of Uniqueness in Scenario Selection Approaches . . . . . . . . . . . . . . 5-14

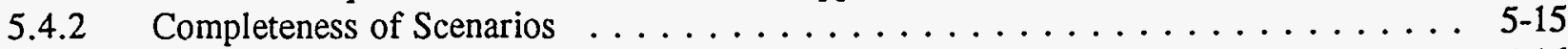

5.4 .3 Probability of Occurrence $\ldots \ldots \ldots \ldots \ldots \ldots \ldots \ldots \ldots \ldots \ldots \ldots \ldots$

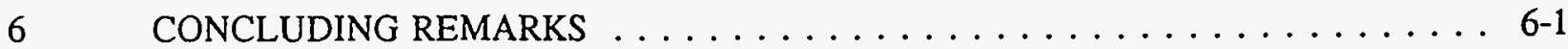

$7 \quad$ REFERENCES $\ldots \ldots \ldots \ldots \ldots \ldots \ldots \ldots \ldots \ldots \ldots \ldots \ldots$ 


\section{FIGURES}

Figure

Page

1-1 Sources of uncertainty in performance assessment $\ldots \ldots \ldots \ldots \ldots \ldots$

2-1 Steps in the NRC/SNL scenario selection approach $\ldots \ldots \ldots \ldots \ldots \ldots \ldots$

2-2 Logic tree used in the NRC/SNL scenario selection approach . . . . . . . . . . . . 2-4

2-3 Segment of event tree connecting FEPs that define scenarios . . . . . . . . . . 2-10

2-4 Top three levels of basaltic volcanism generalized tree . . . . . . . . . . . . . . 2-12

2-5 Tree segment $2\left(\mathrm{TS}_{2}\right)$ in basaltic volcanism tree $\ldots \ldots \ldots \ldots \ldots \ldots \ldots \ldots$

2-6 Seven scenarios (denoted by the pentagons) generated from $\mathrm{TS}_{2}$ due to basaltic volcanism . . . . . . . . . . . . . . . . . . . . . . . . . 2-14

2-7 Example of logic tree used in EPRI studies . . . . . . . . . . . . . . 2-19

2-8 Master logic tree used in Phase 2 of EPRI studies . . . . . . . . . . . . . . 2-20

2-9 Logic tree values and probabilities for node 1 in master logic tree . . . . . . . . 2-21

3-1 Schematic of Swedish FEP screening approach $\ldots \ldots \ldots \ldots \ldots \ldots \ldots$

3-2 Final scenario elements in trial application of UK Nirex Ltd. top-down scenario

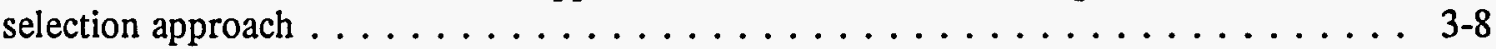

4-1 Components of United Kingdom Department of Environment/Her Majesty's Inspectorant of Pollution environmental simulation approach $\ldots \ldots \ldots \ldots \ldots \ldots$. . . . 


\section{TABLES}

Table

Page

2-1 Number of scenarios for each tree segment considered by Barr et al. (1993) for

basaltic volcanism at Yucca Mountain .................. 2-15 


\section{ACKNOWLEDGMENTS}

This report was prepared to document work performed by the Center for Nuclear Waste Regulatory Analyses (CNWRA) for the Nuclear Regulatory Commission (NRC) under Contract No. NRC-02-93-005. The activities reported here were performed on behalf of the NRC Office of Nuclear Regulatory Research, Division of Regulatory Applications. The report is an independent product of the CNWRA and does not necessarily reflect the views or regulatory position of the NRC.

The authors wish to thank Drs. B.E. Hill, P.C. Lichtner, and G.I. Ofoegbu for their technical reviews and B. Sagar for his programmatic review; their contributions led to significant improvements in this report. 


\section{NOMENCLATURE}

AECL

ANDRA

CCDF

CEC

CNWRA

DOE

ENPA

EPA

EPRI

EPS

ESA

FEPs

FFSM

GSM

HLW

IAEA

HMIP

IPA

NAS

NEA

NRC

NWPA

OECD

PA

SF

SKB

SKI

SNL

SwRI

TRU

UK

WIPP

YM

YMSCP

YMNV
Atomic Energy Canada Limited

France's National Agency for Radioactive Waste Management

Complementary cumulative distribution function

Commission of European Communities

Center for Nuclear Waste Regulatory analyses

U.S. Department of Energy

Energy Policy Act

U.S. Environmental Protection Agency

Electric Power Research Institute

Events and processes

Environmental simulation approach

Features, events, and processes

Far-Field State Model

Geologic Simulation Model

High-level radioactive waste

International Atomic Energy Agency

Her Majesty's Inspectorate of Pollution

Iterative Performance Assessment

National Academy of Sciences

Nuclear Energy Agency

Nuclear Regulatory Commission

Nuclear Waste Policy Act

Organization for Economic Cooperation and Development

Performance Assessment

Spent fuel

Swedish Nuclear Waste Management Company

Swedish Nuclear Power Inspectorate

Sandia National Laboratories

Southwest Research Institute

Transuranic waste

United Kingdom

Waste Isolation Pilot Plant

Yucca Mountain

Yucca Mountain Site Characterization Plan

Yucca Mountain, Nevada 


\section{INTRODUCTION}

Since the 1970s, agencies of the U.S. government and other entities in the United States have been pursuing the development of methodologies-and the associated methods, tools, and techniques-for assessing the long-term performance of high-level radioactive wastes (HLW) repositories located in deep geologic formations. These repositories are to become the final disposal method for HLW and spent fuel (SF) from commercial nuclear power generation as well as HLW from defense related activities.

In 1982, the U.S. Congress enacted the Nuclear Waste Policy Act (NWPA) (Public Law 97-425), later amended in 1987 (Nuclear Waste Amendments Act of 1987). The NWPA established not only the purpose and goals of the HLW management program in the United States, but also the statutory roles and responsibilities of the different government agencies in the program. The U.S. Department of Energy (DOE) was assigned responsibility for the design, construction, operation, and closure of the HLW repository; the U.S. Environmental Protection Agency (EPA) for the development of appropriate regulatory standards which will ensure the protection of the health and safety of the public and of the environment; and the Nuclear Regulatory Commission (NRC) for the implementation of EPA standards in the evaluation of a license application submitted by the DOE.

In 1983, the NRC promulgated its regulation Disposal of High-Level Radioactive Waste in Geologic Repositories, also known as 10 CFR Part 60 (Nuclear Regulatory Commission, 1983). This regulation preceded the issuance of any regulatory standards by the EPA, but makes reference to it in 10 CFR 60.112. In 1985, the EPA promulgated its general standards Environmental Standards for the Disposal of Spent Nuclear Fuel, High-Level, and Transuranic Radioactive Wastes, more commonly known as 40 CFR Part 191 (U.S. Environmental Protection Agency, 1985).

The containment requirements in 40 CFR Part 191 specify that, to determine the long-term ability of the disposal system ${ }^{1}$ to isolate the wastes, a performance assessment (PA) must be conducted. This PA needs to identify the events and processes which are occurring or can occur during the length of the regulatory period and can impact the behavior of the system; estimate the consequences of those events and processes, taking into consideration the inherent uncertainties; and assemble the consequences in a complementary cumulative distribution function (CCDF) of total release of radioactivity to the accessible environment during the first $10,000 \mathrm{yr}$ following repository closure. Scenarios are widely used as a means to postulate those events and processes and, as such, the selection of scenarios is a critical aspect of PA.

In 1987, the courts vacated 40 CFR Part 191 and remanded it to the EPA for revision and repromulgation. In December 1993, EPA proposed a revised version of this regulation applicable to the DOE's Waste Isolation Pilot Plant. EPA is yet to revised the regulation to render it applicable to HLW disposal at Yucca Mountain. In preparing this latter revision of 40 CFR Part 191, EPA will consider recommendations offered by the National Academy of Sciences (NAS), as mandated by the Energy Policy Act (ENPA) of 1992. This legislation requested the NAS to comment on three issues regarding EPA's regulation for HLW disposal: (i) whether a health-based standard on doses to individual members of the public would be reasonable, (ii) whether post-closure oversight of a repository, based on active institutional controls, could prevent an unreasonable risk of breaching the repository's barriers or of causing unacceptable radiation doses to the public, and (iii) whether it is possible to make scientifically supportable predictions of the probability of human intrusion for $10,000 \mathrm{yr}$. Depending on the NAS

Disposal system includes the entombed wastes, the engineered facility, and the host geologic medium. 
recommendations and their consideration by EPA in the revision of 40 CFR Part 191, the nature of the scenarios that need to be considered in a PA may be affected which, in turn, may impact the manner in which scenarios are formulated.

\subsection{PURPOSE AND SCOPE OF REPORT}

In this report, the current status of scenario development or scenario selection (hereinafter "scenario selection") is reviewed, as are the approaches or methods being considered and/or implemented by the major radioactive waste management programs in the United States and in other member countries of the Organization for Economic Cooperation and Development (OECD). Where possible, the application(s) of the different approaches and the results obtained from such application(s) are summarized. For the sake of completeness, the Environmental Simulation Approach (ESA) is also discussed.

It is intended that the reader be provided with information which will allow him/her to capture the salient features of each approach or method herein discussed, and, more importantly, the similarities and differences between the different approaches. Finally, key issues are discussed regarding scenario-selection that are still open and deserve attention.

While the purpose of this report is to discuss and compare different methodological aspects of scenario selection as implemented by major radioactive waste disposal programs in the United States and other countries, it should be noted that there is a suite of issues regarding scenario analysis, the consideration of which are beyond the scope of this report. Example of such issues are: (i) the appropriate regulatory definition of the term "scenario," (ii) the appropriate definition of "repository system," and (iii) the use of a constant probability of occurrence over the entire spatial and temporal domain of interest for phenomena, the probability of which can be a function of space and time, among others. Each of these issues will impact the outcome of a PA, and therefore, investigations aimed at their resolution may be warranted in the future.

\subsection{SCENARIOS AND UNCERTAINTY IN THE FUTURE STATES OF THE DISPOSAL SYSTEM}

A suite of uncertainties can affect the estimation of performance of the disposal system and, therefore, should be accounted for in a PA. The radioactive waste management literature is quite abundant with treatises on the subject which will not be repeated here; the interested reader is encouraged to peruse more in-depth discussions in, for example, Nuclear Energy Agency (1987), Buxton (1989), Nuclear Energy Agency (1989a), Davis et al. (1990), Gallegos and Bonano (1993), Codell et al. (1992), and Thompson and Sagar (1993), among others. Conventionally, the sources of uncertainty affecting a PA are classified into three major categories: (i) uncertainty in the future states of the system, where state is defined as the boundary conditions and forcing function under which the system will evolve; (ii) uncertainty in conceptual models; and (iii) uncertainty in parameters of mathematical models. The relationship among these sources of uncertainty is illustrated in Figure 1-1.

Uncertainty in the future state of the system arises because: (i) the complexity of the system; and (ii) the long-temporal scale over which the evolution of the system needs to be considered preclude any reliable forecasting of such evolution (Davis et al., 1990; Nuclear Energy Agency, 1992). Postulating scenarios-each scenario representing a possible realization of such a future state-is the conventional 


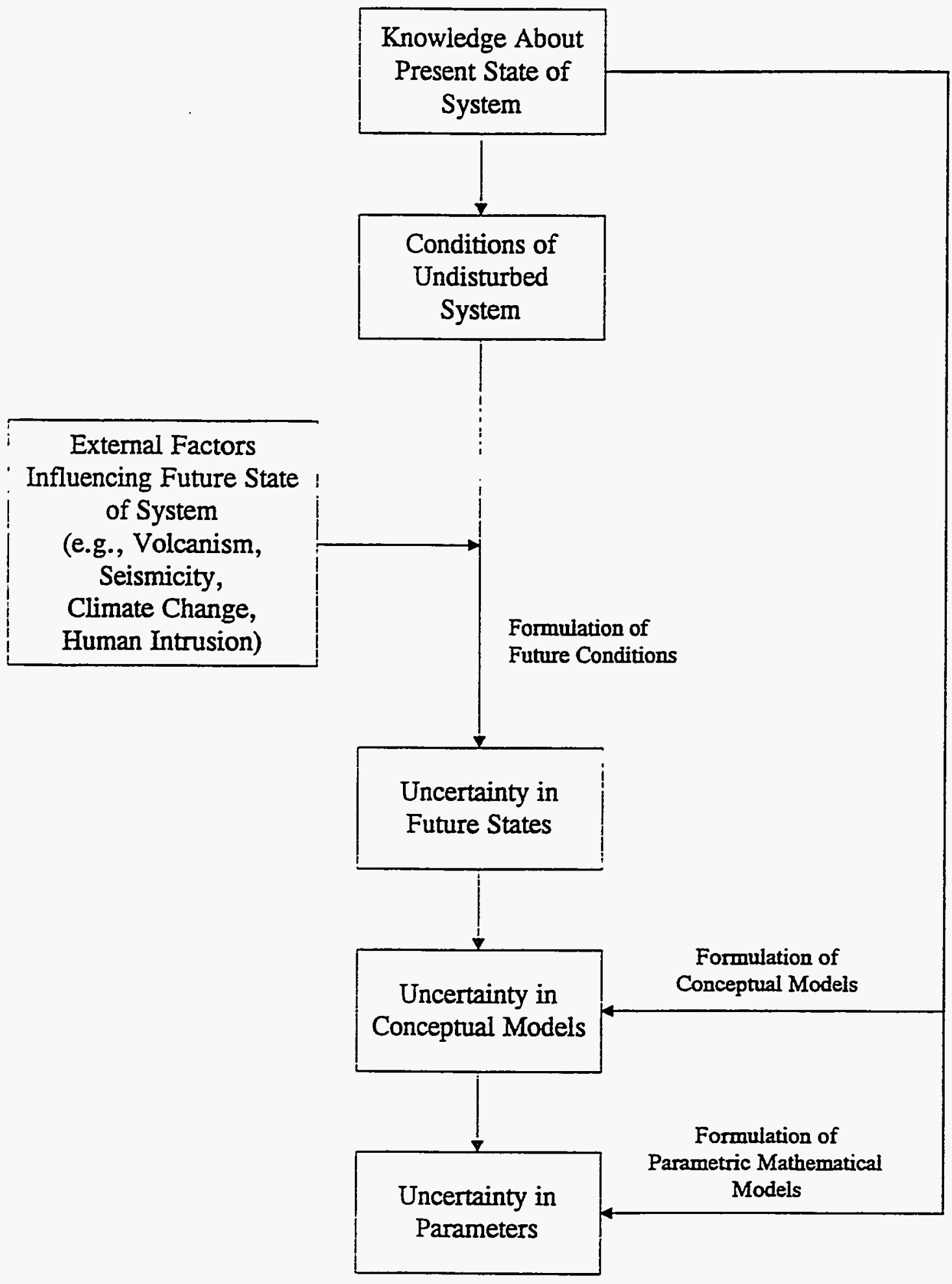

Figure 1-1. Sources of uncertainty in performance assessment 
approach for dealing with this uncertainty. A scenario is a combination of one or more events and processes and, for each scenario, a probability is used to quantify the likelihood of occurrence of the scenario during the regulatory period. In principle, these probabilities will be employed, in conjunction with the estimated consequences of the scenarios, to construct the CCDF required by 40 CFR Part 191 (Bonano and Wahi, 1990; Helton, 1993).

The use of scenarios is an important component of PA for radioactive waste disposal systems being conducted or planned in several other countries (Nuclear Energy Agency, 1992). In general, scenarios provide the context in which PA is conducted because they are the means for the consideration of future conditions at a given disposal site. The selection of scenarios influences the development of models and the collection of data by identifying the events, processes, and conditions that need to be examined in a PA. In several countries the selection of scenarios has served as the framework for conducting discussions among the different program participants; i.e., proponents and regulators of disposal facilities, and other interested groups (Nuclear Energy Agency, 1992).

The use of scenarios as the means to deal with uncertainty in the future states of an engineered system in risk assessment is not restricted to HLW disposal. The use of scenarios in risk assessment for a variety of engineered systems by agencies of the Federal Government is quite common (Nuclear Regulatory Commission, 1992). However, other methods, such as the ESA, have been proposed also as a means for considering uncertainty in the future state of a radioactive waste disposal system. Furthermore, no unique approach exists for arriving at scenarios. Consequently, even among the proponents of the scenario approach, there are differences between the approaches adopted.

\subsection{ORGANIZATION OF REPORT}

following topics:

Besides this introductory chapter, this report consists of another five chapters covering the

- Chapter 2, Scenario Selection Approaches in the United States

- Chapter 3, Scenario Selection Approaches in OECD Countries

- Chapter 4, Environmental Simulation Approach

- Chapter 5, Key Issues in Scenario Selection

- Chapter 6, Concluding Remarks 


\section{SCENARIO SELECTION APPROACHES IN THE UNITED STATES}

Both the DOE and the NRC as the applicant and regulator, respectively, of a license for a HLW repository in the United States have developed PA methodologies to either demonstrate (DOE) or determine (NRC) compliance with the requirements in 10 CFR Part 60 and 40 CFR Part 191. Both the $\mathrm{DOE}$ and NRC are using scenarios to define future conditions that affect the long-term performance of the repository system. The Electric Power Research Institute (EPRI), as the research arm of the electrical power industry in the United States-a stakeholder in the HLW program-is also conducting PA analyses for the proposed HLW repository at Yucca Mountain (YM) which includes analyses of scenarios.

\subsection{SCENARIO APPROACHES USED BY THE NUCLEAR REGULATORY COMMISSION}

\subsubsection{Scenario Methodology by Sandia National Laboratories}

From 1976 to 1991, the NRC contracted to Sandia National Laboratories (SNL) the development of a PA methodology which the former could use in its review of the license application for a HLW repository submitted by the DOE. The SNL originally developed the PA methodology for a HLW repository in bedded salt (Cranwell et al., 1987), and later modified it to render it applicable to basalt (Bonano et al., 1989) and tuff (Gallegos, 1991). The three PA methodologies used the same framework, the major differences being the models necessary to accommodate the different properties and phenomena characteristics of each geologic medium. As part of the original PA methodology for bedded salt, Cranwell et al. (1990) developed a six-step scenario selection procedure. This same procedure was applied in defining scenarios for a HLW repository in basalt (Hunter, 1983). The procedure was also applied to a repository in tuff, but a report was not completed or published. ${ }^{2}$

The scenario selection procedure developed by Cranwell et al. (1990) was first unofficially published in 1982, and therefore is considered the pioneering work in the subject. It is commonly known within the international radioactive waste management community as the "NRC/SNL scenario selection approach" (Nuclear Energy Agency, 1992). This approach consists of the following steps:

(i) Identification of events and processes (EPs) which could have deleterious effects on the long-term performance of the disposal system

(ii) Classification of the EPs to assist in defensible arguments of "completeness"

(iii) Screening of the initial EPs to reduce their number

(iv) Formation of scenarios from the EPs surviving after the screening step

(v) Screening of scenarios

2 R.V. Guzowski (Science Applications International Corporation). Private conversation to E.J. Bonano (Beta Corporation International), November, 1993. 
(vi) Selection of a final set of scenarios for consequence analysis, including the assignment of a probability of occurrence

These steps, illustrated in Figure 2-1, will be discussed further in the following. It should be noted that the identification and classification of EPs are iterative in nature and often implemented simultaneously.

The identification of EPs is aimed at developing as comprehensive a list as possible of those EPs which can have an adverse impact on repository performance. The EPs typically included are both human- and system-induced. Generic lists of EPs, such as that published by the International Atomic Energy Agency (IAEA) (1983), have been developed as an aid to implementing this step.

The second step is the classification of the EPs for the purpose of enhancing the likelihood of completeness. Completeness, in this case, refers to ensuring that all potentially important EPs have been considered. Cranwell et al. (1990) proposed four major classes of EPs: naturally occurring, human-induced, waste-induced, and repository-induced. This particular classification scheme employs origin and physical characteristics as the discriminating factors; however, this scheme is not unique and others which are equally useful have been successfully utilized.

In order to increase the likelihood of completeness, the identification of EPs tends to err on the side of conservatism and include as many EPs as imaginably possible. Thus, the third step in the approach is the systematic screening of the initial EPs. Cranwell et al. (1990) proposed three screening criteria: (i) physical reasonableness; (ii) probability or likelihood of occurrence; and (iii) potential consequence. Physical reasonableness should result in the screening of those EPs the occurrence of which is impossible given the characteristics and properties of the disposal system. EPs with a low probability or likelihood of occurrence can be eliminated from further consideration or combined with others of potentially similar consequences and higher probability. Finally, EPs with small potential consequences are screened out because their inclusion in the PA calculations is unlikely to increase the chance of violating the regulatory requirements.

The surviving EPs are used to construct scenarios from combinations which represent both their occurrence and nonoccurrence. To ensure that all possible combinations of EPs have been accounted for, Cranwell et al. (1990) used a logic tree, such as the one in Figure 2-2. This particular logic tree shows the construction of scenarios from the combination of two release EPs $\left(R_{1}\right.$ and $\left.R_{2}\right)$ and three transport EPs $\left(T_{1}, T_{2}\right.$, and $\left.T_{3}\right)$. The tree starts in the left-hand side with a scenario that includes all EPs known to be active during the regulatory period. One then proceeds from that scenario moving through the different branches of the tree by reaching a node for a given EP that is expected to alter the performance of the system, and deciding whether or not it occurs. Moving up from a decision point ("NO" answer) means that the given EP does not occur, whereas moving down ("YES" answer) means occurrence of the EP. If the answer is "NO" at all decision points, none of the EPs considered occurs and the result is the base-case scenario. The set of possible combinations-hence, scenarios-is listed in the right-hand side of the tree. For each scenario, $\mathrm{R}_{\mathrm{i}}$ or $\mathrm{T}_{\mathrm{j}}$ denotes that the $\mathrm{i}^{\text {th }}$ release EP or the $\mathrm{j}^{\text {th }}$ transport EP has occurred, while $\bar{R}_{i}$ or $\bar{T}_{j}$ means it has not. The total number of scenarios is $2^{\text {n }}$, where $n$ is the total number of EPs considered. One of the difficulties with this approach, also referred to as a bottoms-up scenario approach, is the large number of scenarios which can be generated from a few EPs.

The initial set of scenarios is then screened to reduce their number based on three criteria: (i) physical reasonableness; (ii) probability of occurrence, and (iii) potential consequences-the same 


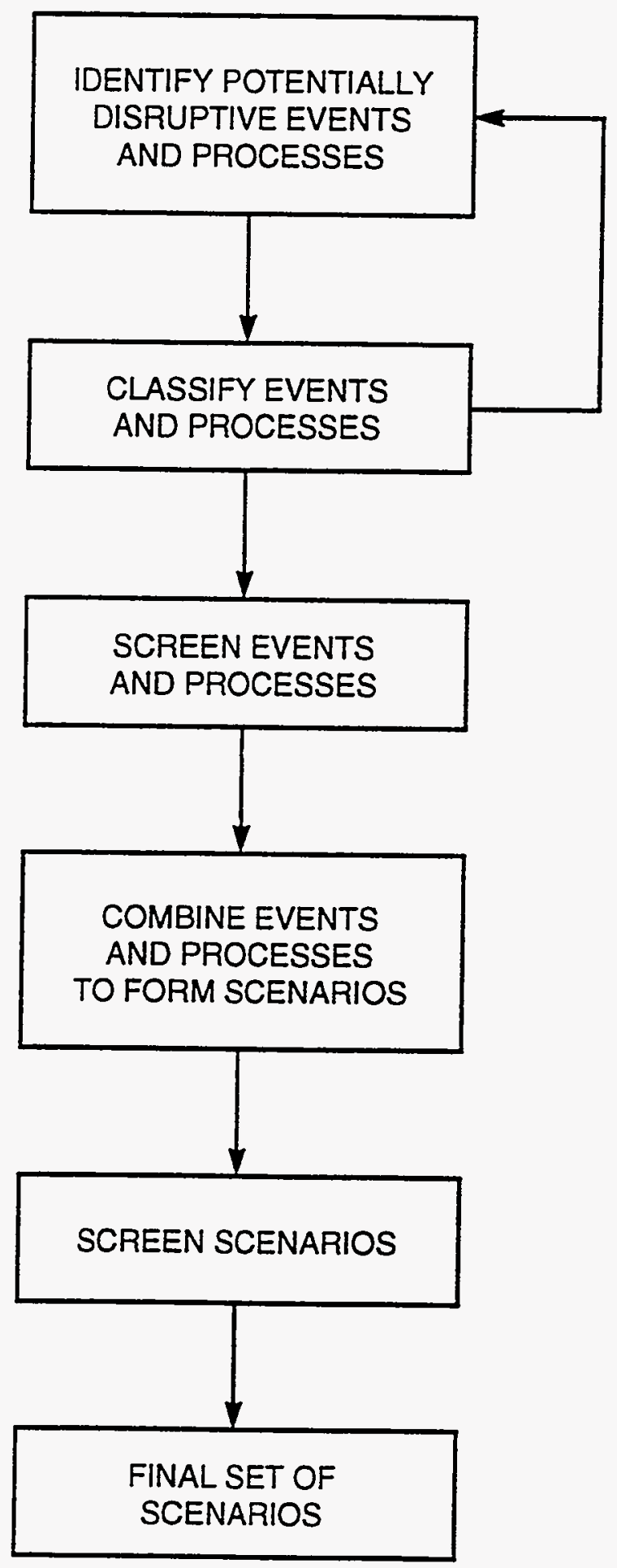

Figure 2-1. Steps in the NRC/SNL scenario selection approach (after Cranwell et al., 1990) 


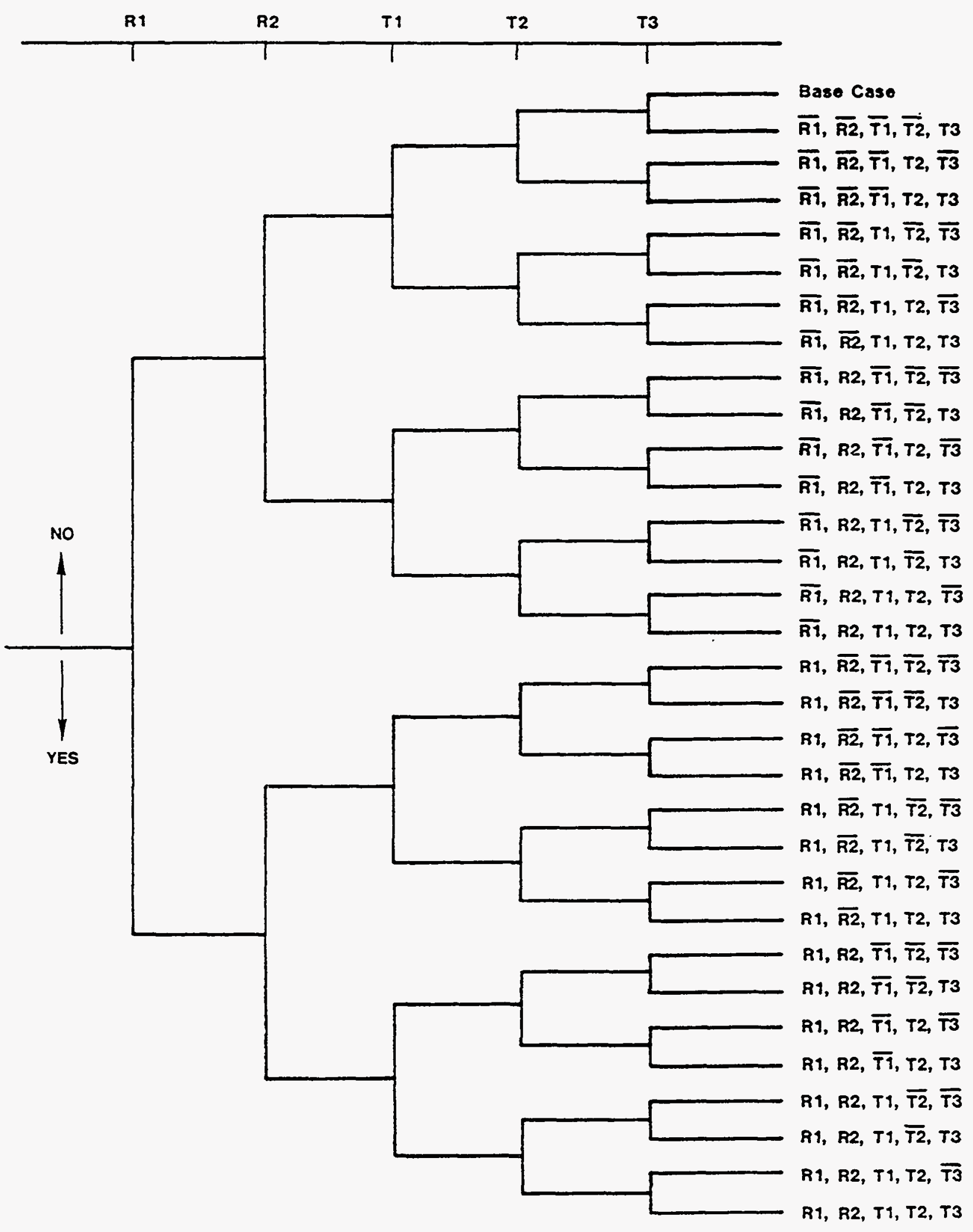

Figure 2-2. Logic tree used in the NRC/SNL scenario selection approach (after Cranwell et al., 1990) 
criteria discussed earlier for the screening of EPs. If the probability of a given EP can be reliably estimated to be less than $10^{-4}$ in $10,000 \mathrm{yr}$, then per guidance in 40 CFR Part 191, the scenario need not be considered further. Because the application of the logic tree as the means to generate scenarios is a purely mechanical exercise, specific combinations of EPs may not be physically possible; therefore, the scenarios representing those combinations are eliminated. The probability of a scenario is conventionally estimated from the probability of the EPs comprising the scenario by assuming that the EPs are statistically independent. Finally, scenarios which do not contribute significantly to the release of radioactivity to the accessible environment can either be combined with other scenarios of similar consequences or eliminated from further consideration.

The final set of scenarios for PA is selected and models which can simulate the attendant EPs in each scenario are implemented. Expert judgment permeates all aspects of this scenario selection approach. Bonano et al. (1990) discuss how such judgments are needed in each of the steps in this approach; the reader is referred to that report for a more in-depth discussion on the use of expert judgments in the NRC/SNL scenario selection approach.

The NRC/SNL scenario selection approach is not without deficiencies; some of the most salient ones raised by critics of this approach are (Nuclear Energy Agency, 1992):

- Can yield an inordinately large number of scenarios

- Cannot account for the time-dependent onset, evolution, and/or interaction of EPs

- Does not allow for the simultaneous occurrence of two or more scenarios

- May lead to underestimation of the risk

Thompson (1988) has been the most staunch critic of this approach. He cited several deficiencies of the scenario approach, such as: (i) ambiguity in the definition of the term "scenario;" (ii) inability to accommodate the temporal onset, evolution, and interactions of the different processes and phenomena affecting repository performance; (iii) lack of scientific basis; and (iv) heavy reliance on subjective judgments; among others. Thompson advocates the use of the ESA as an alternative to the scenario approach that overcomes these deficiencies (the ESA is discussed in Chapter 4). Such criticisms notwithstanding, most radioactive waste management programs in member countries of the OECD have adopted a scenario approach tailored to their respective disposal system, the framework of which has been the NRC/SNL approach (Nuclear Energy Agency, 1992).

\subsubsection{Scenario Approach for Iterative Performance Assessment Exercises}

As part of conducting Phase 1 of its Iterative Performance Assessment (IPA) effort (Codell et al., 1992), the NRC adopted a methodology for the selection of scenarios, the basic difference of which compared to other scenario approaches is the type of the events and processes it considers. For example, the NRC only considers EPs, the source of which is outside the accessible environment. Thus, repositorysystem induced EPs are not considered in the construction of scenarios; instead, such EPs are incorporated in the models and data base used for simulating the evolution of the repository system. Uncertainty in thus EPs is represented through uncertainty in the models and data base needed for the PA. 
The NRC also defined the term "scenario" as a description of one of various ways in which the repository system may evolve over time (Codell et al., 1992).

The scenario methodology used by NRC, at the present time, is a variation of that developed by Cranwell et al. (1990). The methodology has six basic steps: (i) identification of processes and events, (ii) estimation of probabilities for the each of the EPs, (iii) screening of the EPs, (iv) scenario construction, (v) calculation of scenario probabilities, and (vi) screening of scenarios. A comprehensive set of external EPs that could adversely impact the performance of the repository system is identified. If the onset of a given EP is believed to have a significant effect on the PA results, the time of occurrence is included in the description of the EP. Multiple occurrences of an EP are considered as subevents. Historical data, models, and/or expert judgments are used to estimate the probability of occurrence of a given EP. Using this information, EPs in the initial list are screened based on (i) lack of physical reasonableness, (ii) low probability of occurrence, and/or (iii) potentially insignificant impact on repository performance.

EPs retained after the screening step are combined using a logic tree similar to that used by Cranwell et al. (1990) (see Figure 2-2) to form scenario classes. A scenario class is an unique grouping of EPs that does not specify the sequence of the EPs. For each scenario class, specific scenarios are defined from different permutations of the ordering of the EPs. A scenario class, in this context, is equivalent to the definition of scenario used by Cranwell et al. (1990) in the NRC/SNL methodology. The probability of a scenario is determined from the probability of the individual EPs comprising the scenario. If the EPs are statistically independent, the probability of occurrence of the scenario is obtained by a simple multiplication of the individual EPs probabilities. In this case, all scenarios in a scenario class will have the same probability of occurrence. If the EPs are not independent, the calculation of the probability of a scenario will need to account for the existing interdependencies. In this case, each scenario in a scenario class can, in principle, have a different probability of occurrence, for the conditional probability of an EP could depend on the probability of those EPs that precede it in the sequence. Finally, the same criteria used to screen the initial set of EPs are used to screen scenarios.

In IPA Phase 1, the first step of this methodology (i.e., identification of EPs) was applied based on the NRC staff's knowledge of the Yucca Mountain site at the time. Probabilities of the EPs were not evaluated; therefore, the screening of the EPs was primarily based on lack of physical reasonableness and insignificant consequences. The last three steps in the methodology (construction of scenarios, probability of scenarios, and screening of scenarios) were not implemented (Codell et al., 1992). In Phase 1, 20 EPs were considered, but only two were used to construct scenarios: pluvial conditions and drilling. Four scenario classes resulted from these two EPs: (i) undisturbed conditions, (ii) pluvial conditions, (iii) drilling under undisturbed conditions, and (iv) drilling under pluvial conditions.

In IPA Phase 2, the NRC applied the NRC/SNL scenario methodology described in Section 2.1.1 (Park et al., 1994), "scenario" was defined as a postulated future sequence of EPs which is believed to affect repository performance. As in IPA Phase 1, the EPs considered represented either external naturally occurring phenomena or human-induced actions. The first step in the application of the methodology was the definition of the repository system, which is fundamental to the application of this approach because only EPs, the source of which is outside the system's boundary are considered in scenario construction. In IPA Phase 2, the system's boundaries were chosen to coincide with the accessible environment (i.e., $5 \mathrm{~km}$ horizontally from the outer edge of the proposed repository facility and vertically from the land surface to just below the current water table depth. Based on the location of 
the boundary of the repository system, an initial set of generic disruptive EPs was assembled from the list generated for IPA Phase 1 and generic lists in the open literature.

The third step in the application was the screening of EPs using three criteria: (i) lack of physical reasonableness at the site, (ii) insignificant potential consequence, and (iii) low probability of occurrence. In addition, some EPs were combined when the potential effects were deemed to be similar. The screening step led to the following six EPs: extrusive igneous activity, intrusive igneous activity, faulting, seismicity, climate change, and exploratory drilling. Modeling considerations resulted in a combination of some of these EPs to yield the following four EPs used in scenario construction: igneous activity, seismicity, climate change, and exploratory drilling. Using the available data, different methods depending on the EP were used in the fourth step of application to estimate the probability of occurrence for each EP. The fifth step was the combination of the four surviving EPs into a set of mutually exclusive scenario classes.

Sixteen scenario classes were generated in IPA Phase 2 by considering both the occurrence of each EP and its complement (nonoccurrence). The scenario class, consisting of the nonoccurrence of all four EPs, was the undisturbed scenario class. The fact that the occurrence of one or more EPs is included in a scenario class did not imply that all EPs were active simultaneously, rather, it meant that each EP occurs within the 10,000-yr regulatory period. The final step in this application was the calculation of the probability of occurrence for each scenario class. For this calculation, the EPs were considered to be independent of each other and, therefore, the probability of a scenario class was simply the product of the individual EPs' probability constituting the scenario class. The last step in the NRC/SNL methodology scenario class screening was not carried out in the IPA Phase 2.

The NRC believes that limiting the consideration to only external EPs in scenario selection is a way to limit the number of scenarios that need be considered in a PA, at least for a regulatory entity (Codell et al., 1992). Assuring completeness still remains an open issue, and as a check, the NRC may consider the use of a fault-tree approach as well.

\subsection{SCENARIO APPROACH ADOPTED BY THE U.S. DEPARTMENT OF ENERGY}

The DOE has statutory responsibility to design, construct, operate, and decommission and close facilities for the permanent disposal of SF and HLW from commercial nuclear power activities and transuranic (TRU) wastes from defense-related activities. The DOE is, at present, carrying out two major deep geologic disposal programs: the proposed repository at Yucca Mountain, Nevada, for disposal of SF and HLW, and the Waste Isolation Pilot Plant (WIPP) in southeastern New Mexico for TRU waste disposal. The WIPP, as part of a license application, needs to demonstrate compliance with the requirements in 40 CFR Part 191. Even though the EPA is yet to promulgate a regulation for Yucca Mountain, it is expected that the requirements in this regulation will be similar to those in 40 CFR Part 191. Therefore, DOE, NRC, and other Yucca Mountain stakeholders (e.g., EPRI) are using the general guidance in 40 CFR Part 191 until the EPA issues the new regulation. To prepare the license application, the DOE will conduct a PA, a key aspect of which is the consideration of events and processes which may occur during the regulatory period and which could have adverse impacts on the ability of the system to effectively isolate the wastes. Both the YM Project and the WIPP Project have adopted scenario selection approaches as the means to consider these events and processes and estimate 
the effect they may have on the long-term behavior of the repository. These approaches are summarized in the following subsections.

\subsubsection{Yucca Mountain Project}

The first study of potential scenarios pertaining to the proposed repository located in the Topopah Spring tuff at YM was conducted by Ross (1987). Earlier studies, such as Hunter et al. (1982; 1983), applicable to a HLW repository at YM had been carried out, but these were completed prior to the DOE's selection of the Topopah Spring unit as the proposed repository horizon. Ross' study was expanded in the Total System Performance Section of the YM Site Characterization Plan (YMSCP) (Section 8.3.4.13, Chapter 8, Volume VII, Part B) (U.S. Department of Energy, 1988). More recently, Barr and Dunn (1993) have used event trees as the method to construct scenarios for the YM site.

Ross (1987) recommended a set of scenarios for the YM site which warranted further analysis. He examined the list of events and processes that Hunter et al. $(1982 ; 1983)$ developed for that site as well as the more generic list suggested by the IAEA (International Atomic Energy Agency, 1983). From those lists, he identified 58 EPs which may affect the performance of one or more of the six barriers postulated to function at a repository at the YM site (i.e., waste canister, fuel cladding, dissolution of the spent fuel, the Topopah Spring unsaturated welded tuff unit, the Calico Hills unsaturated nonwelded tuff unit, and the saturated tuff zone). The 58 EPs selected led to the construction of 84 sequences which could result in the failure of one or more of the six barriers (a sequence consisted of one or more events and processes). These sequences were then grouped into 17 categories so that all sequences belonging to a given category would have similar consequences. The Ross study concluded with a recommendation that the grouping of the 84 sequences should be the basis for the construction of disruptive scenarios for PA. The list of EPs sequences is extended in the YMSCP to 99 primarily as a result of considering alternative conceptual models of the site not examined by Ross.

Table 8.3.5.13-18 of the YMSCP briefly describes the scenario approach the DOE proposed to use in its licensing strategy for total system performance at the time the YMSCP was published. This approach consists of the following basic steps:

(i) Identification of Relevant Release Phenomena. Starting from generic lists of release phenomena and relying on available site-specific data and information, a shorter list of release phenomena relevant to the particular site of interest is generated.

(ii) Identification of Potentially Significant Events and Processes. The relevant release phenomena identified in Step (i) are then examined based on their likelihood to initiate or promote release scenarios. Those which fit this description are then classified as "potentially significant events and processes."

(ii) Identification of Release Scenarios. Different combinations/sequences of the events and processes deemed significant in Step (ii) are examined. Particular combinations/sequences may be eliminated due to either low likelihood of occurrence of specific events and processes or lack of physical reasonableness.

(iv) Identification of Scenario Classes. Using expert judgments, the release scenarios are grouped into different classes for purposes of modeling. The premise underpinning the 
grouping is that only one mathematical model will be used to simulate the effects of all release scenarios within a given class.

(v) Screening of Scenarios/Scenario Classes. Through consequence analysis and sensitivity analysis, either specific scenarios or an entire scenario class can be eliminated from further consideration.

A more systematic approach proposed for the selection of scenarios for a HLW repository at the YM site has been presented by Barr and Dunn (1993). They proposed the use of event trees as a method for constructing scenarios for the YM PA. Their approach is described and compared to the conventional scenario selection methodology developed by Cranwell et al. (1990) at SNL for the NRC in the early 1980s (hereinafter referred to as the NRC/SNL methodology) in a recent paper presented by Barr and Dunn (1993).

The event-tree method advocated by Barr and Dunn has the same starting point as the NRC/SNL methodology: identification of all the features, events, and processes (referred to by Barr and Dunn as FEPs) which may affect the performance of the disposal system. This information is assembled in what Barr and Dunn called a generalized event tree; the name is used to signify that the tree contains FEPs, not just events. The structure of the tree centers around five fundamental pieces of information:

(i) Definition of the initiating event or process

(ii) Impact of the initiating event or process on the groundwater flow system

(iii) Impact of the initiating event or process on the waste

(iv) Release of waste from the engineered-barrier system as a result of the occurrence of one or more initiating events and/or processes, or

(v) Transport of radionuclides from the repository to the accessible environment due to the occurrence of one or more initiating events and/or processes.

Barr and Dunn claim that organizing the information in this fashion allows the construction of scenarios by starting with an initiating event or process and connecting, in a logical and physically possible manner, combinations or sequences of FEPs which will lead to the release of radionuclides to the accessible environment. A scenario is a single connected path through the tree together with sketches which detail conceptualizations of the physicochemical system; the concept is illustrated in Figure 2-3 extracted from Barr and Dunn (1993). This approach is purported to be better tailored to the development of scenarios for a site, the understanding of which is still evolving. They contrast their approach to that espoused in the NRC/SNL methodology, which they claim is more appropriate for a site in which the information base has reached a sufficiently high level of maturity for a final PA which will provide results to be used in the license application.

Barr and Dunn further claim that their approach permits the decomposition of a large, complex problem into a set of smaller, practically solvable problems. This approach serves a variety of purposes in the evolution of the PA: 


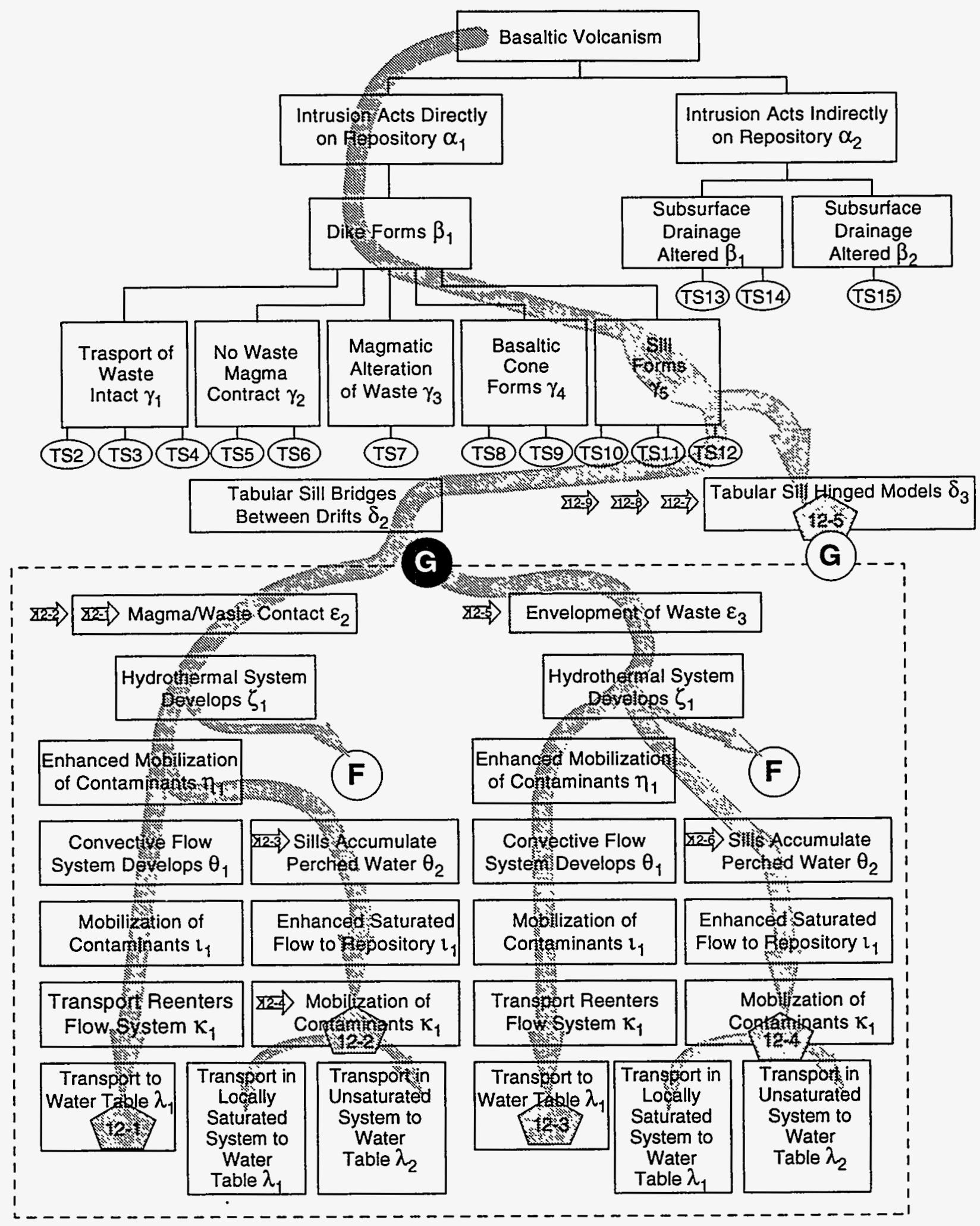

Figure 2-3. Segment of event tree connecting FEPs that define scenarios (after Barr and Dunn, 1993) 
(i) Since some combinations/sequences of FEPs have common members until a given branching point in the tree, the simulation of those combinations/sequences can be carried out using similar, if not identical, models and analyses.

(ii) The event tree and the developed scenarios can be used to establish priorities or program redirections in site characterization.

(iii) The scenarios help keep the gamut of technical activities in the program in the proper context.

(iv) The event trees can be utilized as a bookkeeping system to track scenarios which have been analyzed, are currently under investigation, or are still in need of examination.

(v) The event tree and the developed scenarios can accommodate and retain alternative conceptual models arising from different interpretations of the available data.

The principal investigators in the YM project play key roles in the development of the event tree, in the construction of the scenarios, and in the level of detail with which each branch in the tree is described. The event tree containing the FEPs is constructed "using information, interpretations and speculations provided by the principal investigators (PIs)... working on the Yucca Mountain Project," state Barr and Dunn (1993). The PIs apparently are the individuals that determine the combinations/sequences of FEPs which constitute a given scenario. Finally, their conceptualizations of the system determine the level of detail with which a given combination/sequence is described and analyzed. Barr and Dunn (1993) note that PIs did not agree on the completeness of the proposed conceptualizations.

Barr et al. (1993) applied the approach described by Barr and Dunn (1993) to the construction of scenarios from basaltic igneous activity at YM. These authors start by assuming that basaltic igneous activity includes both intrusive and extrusive modes, and use the general term basaltic volcanism to refer to both modes. They developed a basaltic volcanism generalized event tree divided into a series of levels, starting from general levels at the top of the tree (denoted as the $\alpha$ level) and proceeding down through the tree with each subsequent level representing more detail in terms of the FEPs and conceptualizations of their consequences. For example, Figure 2-4 shows the top three levels (the $\alpha, \beta$, and $\gamma$ levels) of the basaltic volcanism generalized tree. Following the $\gamma$ level, in the left-hand side of the tree (under the branch Intrusion Acts Directly on Repository) and the $\beta$ level on the right-hand side (under the branch "Intrusion Acts Indirectly on Repository"), there are 14 tree segments denoted as $\mathrm{TS}_{\mathrm{i}}(\mathrm{i}=2$ to 15$)$. These tree segments represent the lower levels and subsequent branches of the generalized event tree for basaltic volcanism. It should be noted, however, that $\gamma_{1}$ (Transport of Waste Intact) is in reality a subset of $\gamma_{4}$ (Basaltic Cone Forms). Figure 2-5 shows the rest of the levels and branches of $\mathrm{TS}_{2}$, and Figure 2-6 presents the seven scenarios generated for this tree segment (denoted by the seven pentagons). That is, there are seven different scenarios by which intact waste can be transported to the land surface as a result of basaltic volcanism creating an intrusion directly into the repository and the subsequent formation of a dike which intersects the waste.

The process just described was applied to all 14 tree segments and yielded 69 scenarios distributed in the manner listed in Table 2-1. Given that this application resulted in 69 plausible scenarios due solely to basaltic volcanism, it is fair to say that, similar to the NRC/SNL scenario selection approach, the approach advocated by Barr and Dunn (1993) will lead to the initial generation of a large 


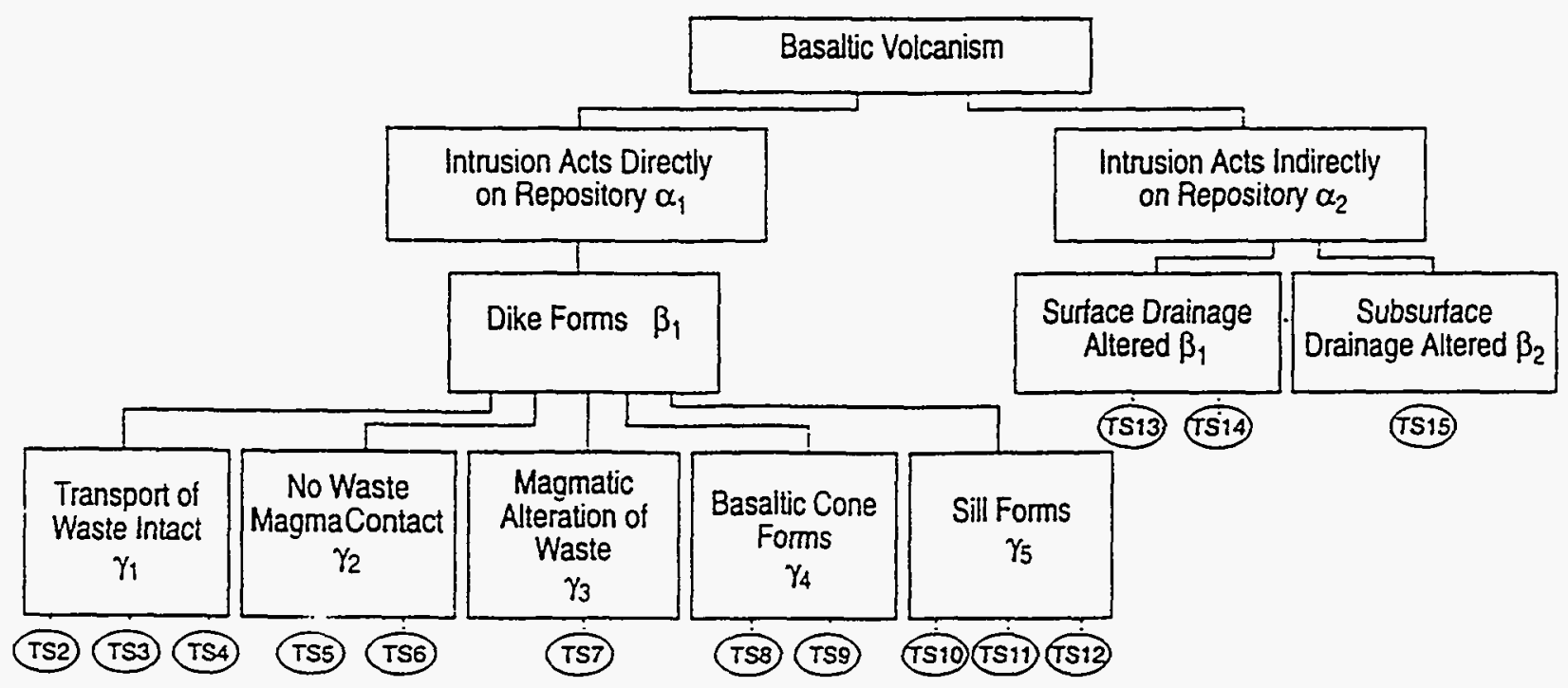

Figure 2-4. Top three levels of basaltic volcanism generalized tree (after Barr et al., 1993)

number of scenarios. However, it is also fair to say that the initial list will be subjected to screening criteria and, in that case, only a few scenarios will survive (Barr and Dunn, 1993). Finally, it should be noted that neither Barr and Dunn (1993) nor Barr et al. (1993) discuss how the probability of occurrence of scenarios in their approach will be estimated.

\subsubsection{Waste Isolation Pilot Plant Project}

Since the early 1970 s, several studies have been conducted to identify what eventually constitute scenarios for deep geologic disposal in bedded-salt formations in the southwestern United States. Some of these studies were specifically aimed at the region where the WIPP is located, while others were for disposal at generic bedded-sait sites. Some of the earlier studies (e.g., Clairborne and Gera, 1974) did not apply structured scenario selection procedures. With subsequent studies, the development of scenarios for the WIPP site has become more structured and systematic.

Bingham and Barr (1979) published the results of a systematic approach to identify scenarios for the WIPP. These authors defined the term scenario as the hypothetical sequence of events leading to radionuclide release from the repository. Each scenario in that study consisted of: (i) a release event that 


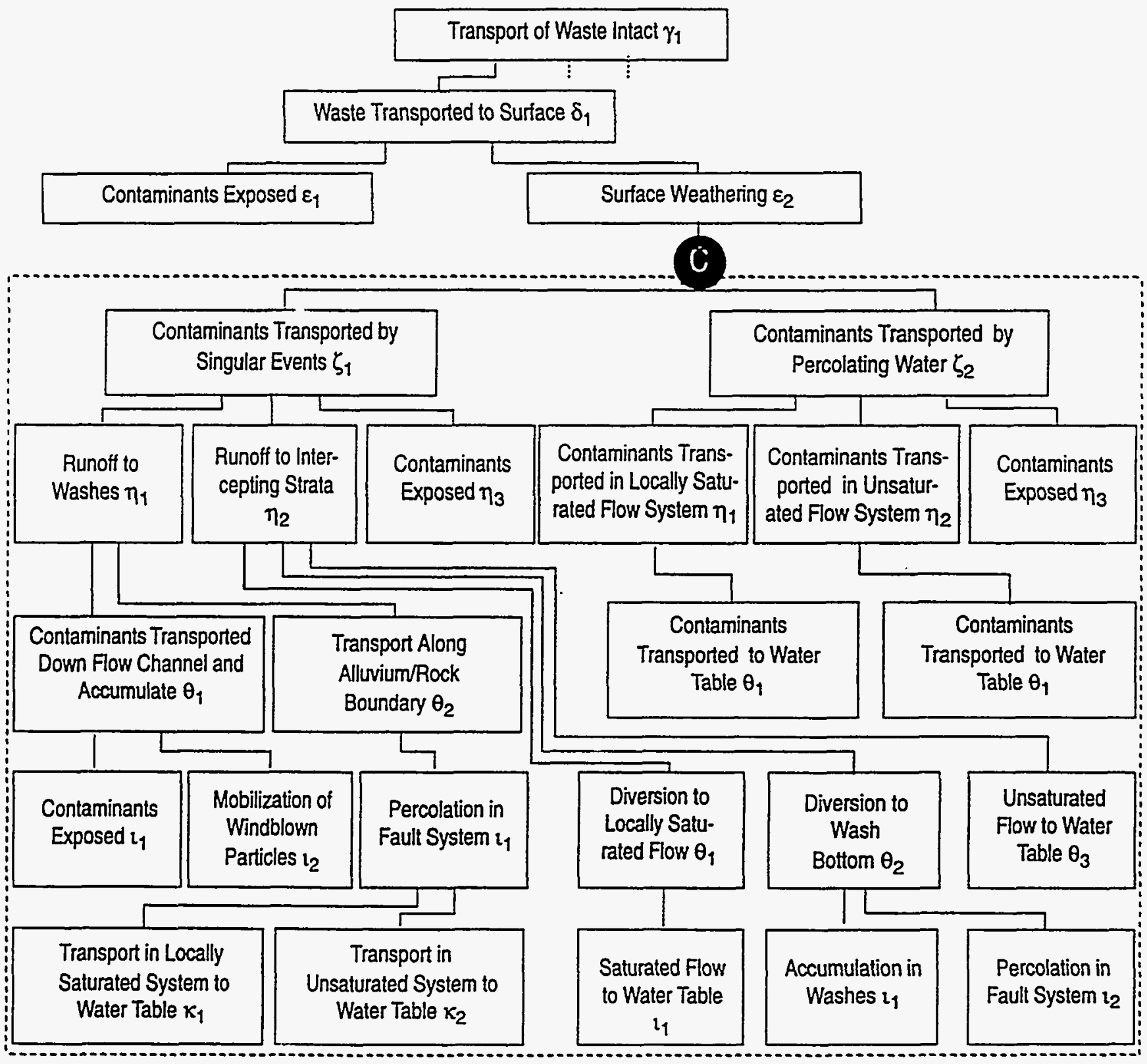

Figure 2-5. Tree segment $2\left(\mathrm{TS}_{2}\right)$ in basaltic volcanism tree (after Barr et al., 1993) 


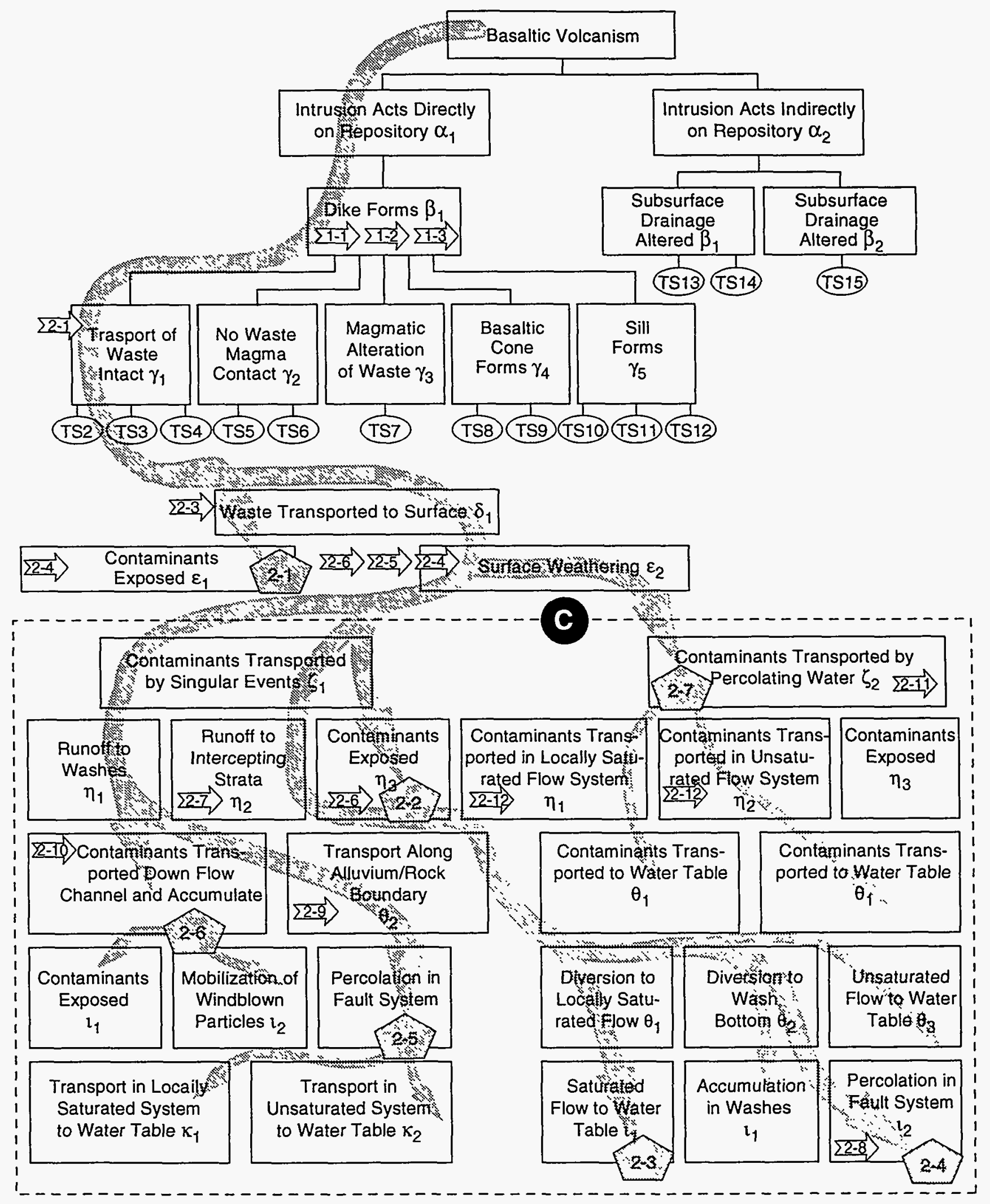

Figure 2-6. Seven scenarios (denoted by the pentagons) generated from $\mathrm{TS}_{2}$ due to basaltic volcanism (after Barr et al., 1993) 
Table 2-1. Number of scenarios for each tree segment considered by Barr et al. (1993) for basaltic volcanism at Yucca Mountain

\begin{tabular}{|c|c|}
\hline Tree Segment & $\begin{array}{l}\text { Number of } \\
\text { Scenarios }\end{array}$ \\
\hline $\mathrm{TS}_{2}$ - Waste transported to surface & 7 \\
\hline $\mathrm{TS}_{3}$ - Hydrothermal system develops & 4 \\
\hline $\mathrm{TS}_{4}-$ New fractures alter hydraulic system & 3 \\
\hline $\mathrm{TS}_{5}$ - Container is disturbed by microseisms & 6 \\
\hline $\mathrm{TS}_{6}$ - Container is undisturbed by microseisms & 8 \\
\hline $\mathrm{TS}_{7}$ - Magmatic alteration of waste & 5 \\
\hline $\mathrm{TS}_{8}$ - Waste is fragmented and entrained & 7 \\
\hline $\mathrm{TS}_{9}$ - Waste is entrained in ash plume & 7 \\
\hline $\mathrm{TS}_{10}$ - Drift void space is filled & 4 \\
\hline $\mathrm{TS}_{11}$ - Sill bridges between drifts & 3 \\
\hline $\mathrm{TS}_{12}$ - Tabular sill bridges between drifts & 4 \\
\hline $\mathrm{TS}_{13}$ - Surface drainage altered, surface damming, ponding & 4 \\
\hline $\mathrm{TS}_{14}$ - Surface drainage altered, surface damming, direction of flow altered & 4 \\
\hline $\mathrm{TS}_{15}$ - Subsurface flow altered & 3 \\
\hline Total number of scenarios due to basaltic volcanism & 69 \\
\hline
\end{tabular}

breaches the repository; (ii) a mechanism for transporting the radionuclides through the breach; (iii) the elapsed time between closure of the repository and the release of radionuclides; (iv) the response of the geologic medium to the breach; $(v)$ the radionuclide inventory in the waste at the time of the release; and (vi) the physical and chemical conditions of the waste at the time of the release. Bingham and Barr identified 19 initiating events which led to the development of 92 different scenarios. They estimated a probability for each of the scenarios in order to rank them in terms of relative importance. Five of the scenarios identified by Bingham and Barr were used in the Final Environmental Impact Statement for the WIPP (U.S. Department of Energy, 1980a; 1980b).

Hunter (1989) modified the approach used by Bingham and Barr (1979) to identify scenarios for use in the first iteration of the annual PA exercise for the WIPP. She examined a wide range of initiating events which have been postulated for the WIPP (Clairborne and Gera, 1974; Bingham and Barr, 1979) as well as for deep geologic disposal in generic bedded-salt sites (Arthur D. Little, Inc., 1980; Cranwell et al., 1990) for their applicability to the WIPP site. She evaluated a total of 24 events 
and eliminated 14 of them based on: (i) physical reasonableness; (ii) probability; (iii) possible consequence; and (iv) regulatory guidance (Hunter, 1989). The ten retained initiating events were:
(i) Normal groundwater flow
(ii) Climate change
(iii) Drilling of exploratory boreholes
(iv) Solution mining
(v) Seal performance
(vi) Effects of drilling into brine reservoir below repository
(vii) Leaching of solid waste
(viii) Nuclear criticality
(ix) Waste/rock interactions
(x) Waste effects

The last two events were later eliminated because they were not deemed to be initiating events.

Guzowski (1990) adopted the NRC/SNL scenario selection methodology (Cranwell et al., 1990) as the approach to use in the selection of WIPP scenarios. The starting point for the application of this methodology was the eight initiating events arrived at by Hunter (1989). Guzowski (1990), however, argued that Hunter should have also included the emplacement of withdrawal wells as an initiating event; he added this event to Hunter's list. As a result of his analysis, he concluded that of the nine initiating events, five were expected to occur during the $10^{4} \mathrm{yr}$ regulatory period and, hence, were folded into the base-case scenario for the WIPP PA. This left the following four initiating events for the construction of scenarios:

- Potash mining outside the WIPP controlled area

- Drilling through a waste-filled room or drift and into a brine pocket under the repository

- Drilling through a room or drift without intersecting a brine pocket

- Emplacement of a withdrawal well

Guzowski (1990) further concluded that, due to the geological stability of the region where the WIPP is located, initiating events due to natural processes are negligible.

Guzowski (1990) implemented the NRC/SNL methodology to construct scenarios from these initiating events. He then attempted to screen the scenarios based on three criteria: physical reasonableness, probability, and consequence. He concluded that all combinations of the initiating events 
were physically reasonable; he did not apply either of the other two criteria. However, preliminary analyses by Marietta et al. (1989) suggested that the potash mining and the well-emplacement events could be safely neglected because cumulative release due to these events were insignificant during the first $10^{4}$ yr following repository closure. Consequently, scenarios due to only two initiating events-drilling through waste-filled room or drift with and without intersecting a pressurized brine pocket-are the only ones being considered in the ongoing WIPP PA calculations (Sandia National Laboratories, 1992; 1993).

Guzowski (1991) continued the analysis of the drilling scenarios by examining different techniques for the estimation of the probability of occurrence. He evaluated four probability estimation techniques proposed earlier by Guzowski and Cranwell ${ }^{3}$ and Campbell and Cranwell (1988):

(i) Probability models (Classical and Poisson)

(ii) Frequentist approach

(iii) Mathematical modeling

(iv) Subjective judgment

He proposed that to estimate the drilling probability, four major factors need to be considered: (i) the occurrence of drilling at the location of the waste panels; (ii) the depth of boreholes equating or exceeding the depth of the waste panels; (iii) the intersection of boreholes with a room or drift filled with waste rather than with the pillars between rooms and drifts; and (iv) the number of boreholes drilled to a depth equal to or exceeding the depth of the waste panels.

Each of the four probability estimation models were evaluated in terms of its ability to address each of the four aforementioned factors. Guzowski (1991) determined that the unambiguous definition of the parameters needed to estimate the drilling rate for use in the probability models did not allow their application with any degree of confidence. The lack of data regarding past exploratory boreholes which intersect waste-filled panels precluded the use of frequentist techniques. Finally, he concluded that the probability of drilling into the WIPP repository, for all practical purposes, will be based solely on expert judgments.

Drilling rates being used to estimate the probability of intrusion into the WIPP repository panels in the current PA exercises have been estimated using subjective judgments from several groups of experts (Hora et al., 1991).

\subsection{SCENARIO ANALYSIS IN ELECTRIC POWER RESEARCH INSTITUTE STUDIES}

The EPRI has developed and demonstrated a risk-based methodology to study the performance of a hypothetical HLW repository at YM. This work was conducted in two phases (McGuire, 1990;

3 Guzowski, R.V., and R.M. Cranwell, Scoping Report on Techniques for Determining Probabilities of Disruptive Events and Processes at or near High-Level Radioactive Waste Repositories, Letter Report from Waste Management Systems Division, Sandia National Laboratories to Division of Waste Management, Office of Nuclear Material Safety and Safeguards, U.S. Nuclear Regulatory Commission. 
1993), with the second phase simply expanding the approach used in the first phase. Scenarios were identified as part of this demonstration.

A group of experts covering a wide range of scientific and policy disciplines was assembled to provide judgments which reflect uncertainties in scientific techniques, assumptions, and data and parameters. In Phase 1 (McGuire, 1990), experts in climatology, tectonics, volcanology, rock mechanics, hydrology, geochemistry, and waste-package engineering were queried. In Phase 2 (McGuire, 1993) the scientific disciplines represented by the experts were expanded to include human factors, nuclear physics, and nuclear engineering.

Logic trees were used as the means to organize and aggregate the judgments offered by the experts in a manner suitable for the calculational aspect of the study (see Figure 2-7). This approach was identical to the one used earlier in the EPRI-sponsored studies of earthquake hazards in both California and the eastern United States. The logic trees were used to track the effects of an external event or process on the behavior of the repository. The trees started with a node representing the external event or process. Out of that node, two or more possible outcomes were identified, each outcome representing a branch. The end of each branch represents another node from which two or more outcomes are possible. The procedure continues to repeat itself for each node and for each branch until all inputs and interactions needed for the calculations have been considered. The decision that the tree is complete relies on subjective judgments. Each branch in the logic tree is assigned a conditional probability which depends on the probability of the branches which preceded it and led to the given node. The end result is a set of parameters and associated probabilities needed for the assessment. The structure of a logic tree is critical because it represents those inputs, scenarios, assumptions that are independent or are conditional on other inputs, scenarios, assumptions, etc.

Figure 2-8 shows the master logic tree used in Phase 1 of the EPRI study (McGuire, 1990). Climate-change effects, the first node in the logic tree, was represented by the value of the next flux (infiltration) (see Figure 2-9). The effect of earthquakes, in terms of induced canister ruptures and rise of the water table, are nodes 2 and 3 , respectively. The possible impact of volcanic activity are represented as (i) the direct effect of a volcano (node 4), and (ii) possible changes to the hydrologic system (node 5). The reader is encouraged to review the report by McGuire (1990) for more detail on the rest of the nodes of the logic tree.

As aforementioned, Phase 2 (McGuire, 1993) was an extension of Phase 1; the most salient: changes being the use of more advanced models and the inclusion of a human-intrusion model in Phase 2. The human-intrusion model considered societal changes, the preservation of knowledge about the repository, and the future value of resources to estimate the effects of drilling and excavation. The basic logic tree used in Phase 1 remained unchanged, except for the addition of the human-intrusion model.

The approach used to identify possible scenarios and the manner in which these are represented is different from the approaches used by the NRC. While the EPRI approach uses logic trees is similar to the two NRC approaches (NRC/SNL methodology and the NRC IPA scenario selection approach) discussed earlier in this chapter, it differs from the latter in two ways. First, the NRC approach propagates the initiating event or process through the logic tree, and the resulting scenarios are combinations of events and processes (e.g., pluvial conditions and drilling) that for which models are then developed to simulate the effects of the scenarios. The EPRI approach propagates the manner in which an event or process is manifested (e.g., net flux and change in water table elevation) through the tree. Second, the applications to date of the NRC approach has only considered events that are statistically 


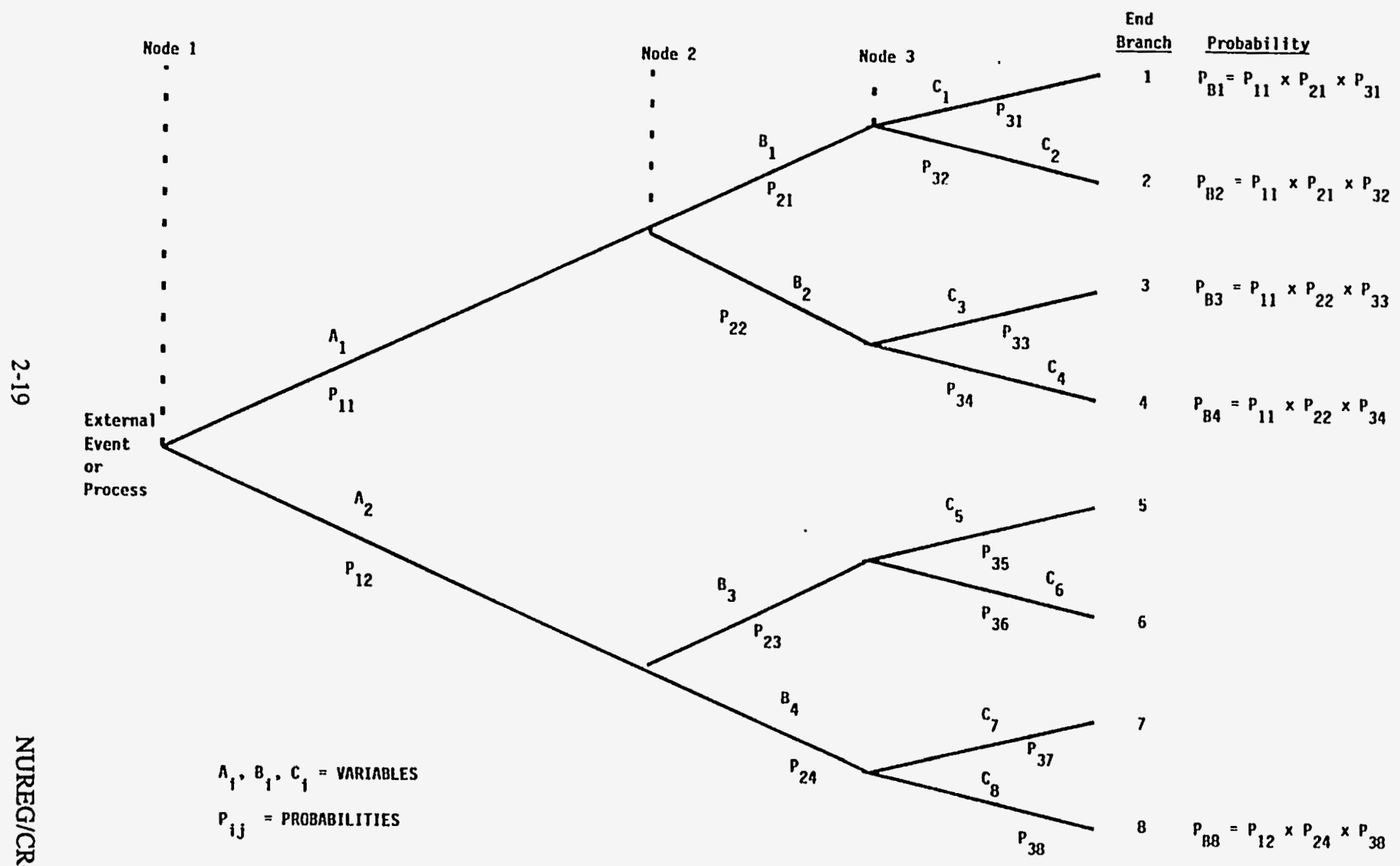

Figure 2-7. Example of logic tree used in EPRI studies 


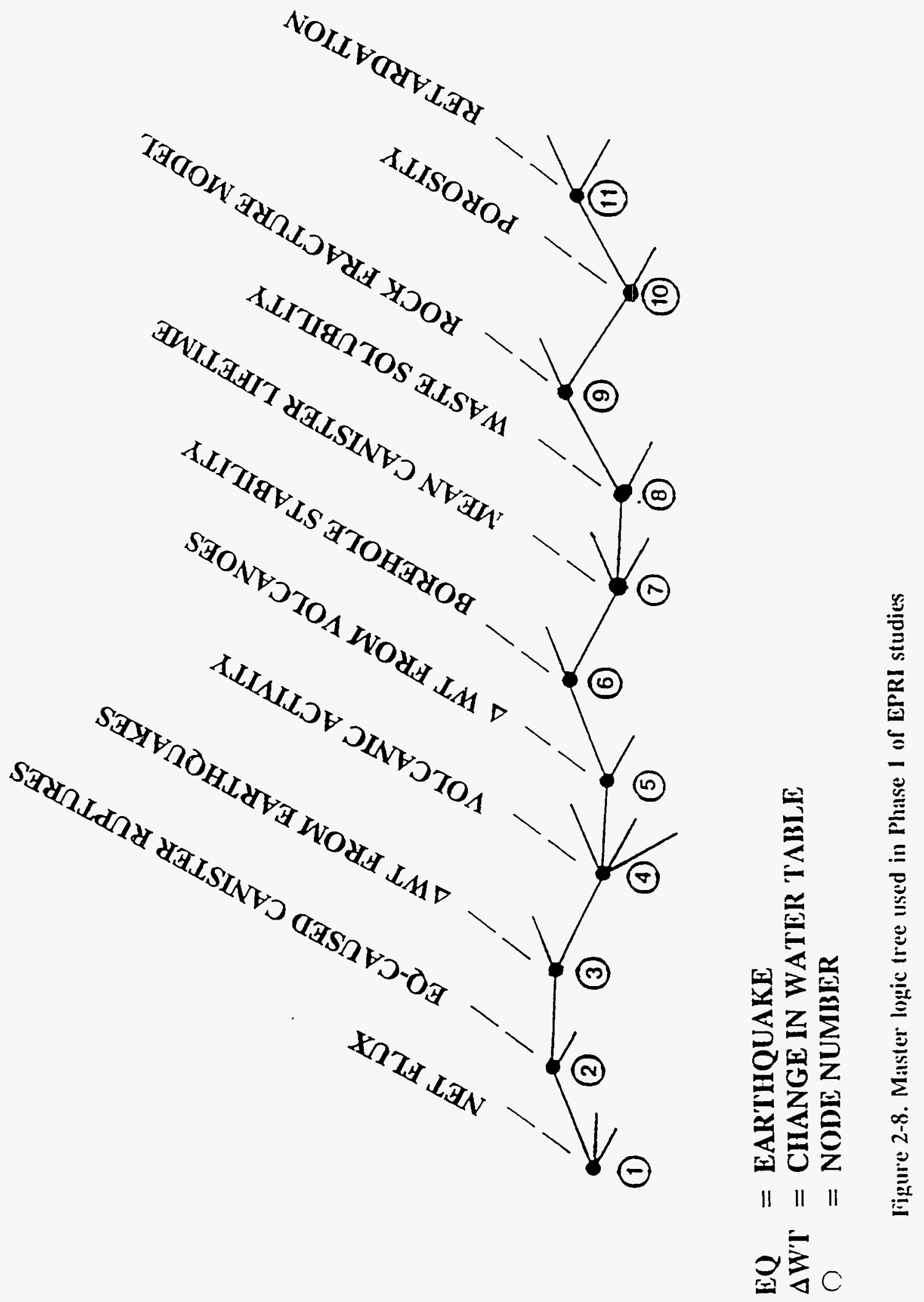




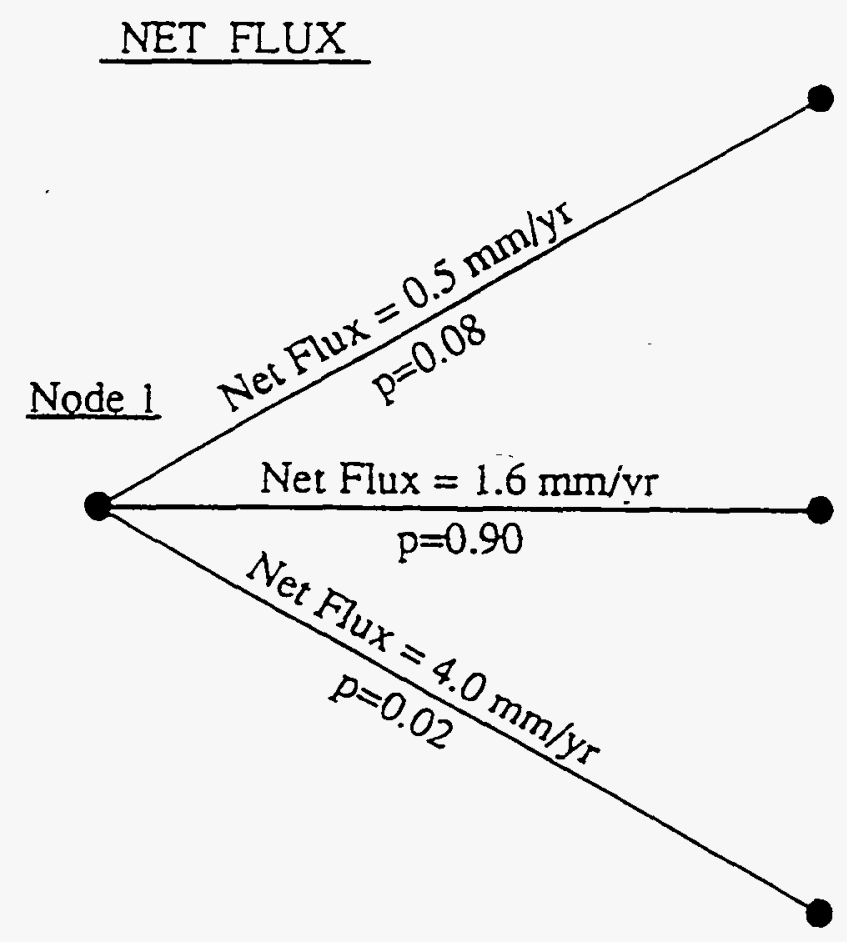

Figure 2-9. Logic tree values and probabilities for node 1 in master logic tree

independent, whereas the EPRI approach factors in the dependence of the probability of an effect on the probability of the effects in the previous branches of the tree.

The differences between the EPRI approach and that proposed by Barr and Dunn (1993) seems to be that the latter propagates events through the tree, while the former propagates the effects of events. In principle, both approaches consider multiple interpretations of the available information in the construction of the tree. In the EPRI approach, multiple interpretations are expressed in terms of multiple values of variables representing the net effect of an event; e.g., various values of net flux caused by climate change (see Figure 2-9). Barr and Dunn consider different interpretations as multiple conceptual models; each conceptual model constitute a different branch of the event tree. In principle, both approaches can estimate conditional probabilities for each of the branches of the tree. However. neither Barr and Dunn (1993) nor Barr et al. (1993), who applied the former's approach, estimated probabilities for the branches of their event trees.

The main advantage of the logic tree used by EPRI is that it provides a framework for the structuring and documentation of multiple interpretations. Its major drawback may the difficulty to capture complex interactions and dependencies in the conditional probabilities for the branches of the tree. 
The EPRI approach, similar to other approaches discussed in this report, relies considerably on the use of subjective expert judgments to construct the logic tree. 


\section{SCENARIO SELECTION APPROACHES IN THE ORGANIZATION FOR ECONOMIC COOPERATION AND DEVELOPMENT COUNTRIES}

The member countries of the OECD have led the way in the development and implementation of PA approaches for evaluating the disposal of radioactive wastes. As a result, national waste management programs in OECD countries have developed approaches for addressing the evolution of the environment and its potential impact on the behavior of the repository. The majority of the national programs have adopted the use of scenarios as the means to deal with uncertainty in the future evolution of the system. The notable exception is the United Kingdom (UK) Department of Environment/Her Majesty's Inspectorate of Pollution which advocates the ESA, and is discussed in Section 4.1.

In 1987, the OECD's Nuclear Energy Agency established the Scenario Working Group to review scenario selection techniques used in PA by the different national programs. The working group completed its deliberations in 1991 and the Nuclear Energy Agency (NEA) published a report summarizing the findings in 1992 (Nuclear Energy Agency, 1992). Scenario approaches used by several of the OECD countries are summarized below.

One notable difference between the NRC/SNL scenario selection methodology (Cranwell et al., 1990) and the approaches used in other OECD countries is that the latter are site-specific while the former offers a generic framework which could be applied to different sites. As a matter of fact, a number of scenario-selection exercises in OECD countries have started with the generic NRC/SNL approach and have customized it to render it applicable to a specific site.

\subsection{CANADIAN SCENARIO SELECTION APPROACH}

Atomic Energy of Canada Limited (AECL) adopted the NRC/SNL scenario selection methodology and customized it, in a pragmatic and practical manner, to render it specifically applicable to the disposal of radioactive wastes generated from CANDU ${ }^{\circ}$ reactors in plutonic rocks of the Precambrian Shield (Stephens and Goodwin, 1990).

This scenario selection approach relied almost exclusively on expert judgments. A group of 15 experts (hereinafter referred to as the group) was assembled to carry out all steps in the scenario development process. This group was augmented and supported, as necessary, by technical staff from the AECL Research waste management program. The group first agreed to definitions of terms to be used in the process. The two most significant terms defined were (Stephens and Goodwin, 1990):

- Factor, is any feature, event, or process which could influence the performance of any component of the disposal facility

- Scenario, is a combination of factors which could affect the ability of the disposal facility to immobilize and isolate the nuclear fuel wastes

The scenario development process consisted of six major steps following the general guidelines offered by Cranwell et al. (1990). 
Over 1,000 factors were initially identified which could potentially affect the performance of one or more of the three major components of the disposal system (the vault or repository, the geosphere, and/or the biosphere). Once the list was completed, the group combined the factors into general headings or general factors, and reduced the number to 270 .

To gain confidence in the comprehensiveness of the list of factors, the group organized and ordered the factors in a variety of ways. This was done with the hope that any potentially important factors missed in the first step would be identified. The classification considered six major categories:

- Type of factor (e.g., feature, event, or process)

- Component of disposal system affected (e.g., vault, geosphere, or biosphere)

- Origin of factor (naturally occurring, vault-induced, or human-induced)

- Mode of action of factors (e.g., biological, chemical, or physical)

- Sub-component(s) affected by occurrence of factor (e.g., within vault, waste form, container, backfill, etc.)

- Pathways by which the critical group of humans is affected by the occurrence of a factor (e.g., ingestion, inhalation, or external exposure)

The 270 factors were screened on the basis of whether or not they were sufficiently important to require quantitative evaluation. Only those factors judged to be sufficiently important were considered in the construction of scenarios. Those factors determined not to meet the sufficiently important criterion were eliminated only if two conditions were met (Stephens and Goodwin, 1990):

- The decision to eliminate a factor had to be unanimous among all members of the group

- The reason(s) for eliminating a factor had to be thoroughly documented (including any qualitative evaluations performed to support the decision)

Some factors did not meet the sufficiently important criterion because they were outside the scope of the PA, that is, they did not apply to waste generated from the operation of CANDU ${ }^{\circ}$ reactors, disposal in the plutonic rocks of the Precambrian Shield, titanium alloy containers, etc., or they could be eliminated using arguments based on the Canadian regulatory criteria (e.g., factor judged to be significant only after the regulatory period has elapsed). Out of the 270 factors considered, 145 were deemed to need qualitative treatment only and 125 to require a quantitative evaluation. The latter were then used to construct scenarios, while the former were not considered further.

Using the 125 factors which require quantitative evaluation, the group proceeded to construct scenarios to be simulated in the PA. The approach used by the group to arrive at these scenarios deviated from the event-tree approach suggested by Cranwell et al. (1990). A central scenario was constructed which includes the most probable and complete list of factors by which waste can be released from the vault, migrate through the geosphere, reach the biosphere, and lead to doses to humans. The aim of the central scenario was to include as many factors as possible; such factors were expected to be always important, occur frequently, and/or proceed to a significant degree over the time scales of interest in the 
PA. A factor was excluded from the central scenario if: (i) it was deemed to be important only rarely or under unusual circumstances; (ii) its presence was incompatible with the presence in the central scenario of an apparently more important factor; and/or (iii) its exclusion resulted in a simplification of the assessment without compromising its results. A total of 117 factors, out of the 125 deemed to be important, were included in the central scenario.

Those factors not included in the central scenario were called Residual Factors and were employed in the construction of Alternative Scenarios. There were a total of 8 residual factors, which led to the initial construction of 255 alternative scenarios (e.g., the number of possible alternative scenarios is given as $2^{r}-1$, where $r$ is the number of residual factors). The 255 possible alternative scenarios were deemed to be an impractical high number, and the group decided that, for the PA, a smaller number of scenarios was desirable. The group, therefore, reexamined the residual factors to determine whether their number can be further reduced. This exercise resulted in the elimination of two residual factors, the deferral of one to a later date, the combination of four into a single factor, and the retention of another factor unchanged. This exercise reduced the original eight residual factors to two (borehole-seal failure and high-demand well); consequently, the number of alternative scenarios was three (one scenario each for each of the two residual factors and a third one for the combination of both factors).

The group defined each of the four scenarios (the central scenario and the three alternative scenarios) in terms of the processes and phenomena which needed to be simulated in each one. This definition included information regarding the temporal sequence of the factors in a given scenario and their duration. Using information from a hypothetical disposal site at the Whiteshell Research Area in Ontario, Canada, the group assigned a probability of occurrence to each of the four scenarios: 0.01 for both the high-demand well and borehole-seal failure scenarios, 0.0001 for the combination scenario (high-demand well and borehole-seal failure), and 0.9899 for the central scenario.

\subsection{SWEDISH SCENARIO SELECTION APPROACH}

In 1988, the Swedish Nuclear Waste Management Company (SKB) and the Swedish Nuclear Power Inspectorate (SKI) started a joint scenario selection exercise for a hypothetical SF and HLW repository in crystalline rock (Andersson et al., 1989; Andersson and Eng, 1990). Both SKB and SKI recognized that the Swedish radioactive waste disposal program could yield significant benefits if they agree on a procedure to develop scenarios prior to the commencement of the licensing process.

The starting point of the SKB/SKI scenario exercise was the NRC/SNL scenario selection methodology (Cranwell et al., 1990). One important deviation from this methodology, though, was the introduction of the so-called Process System. The process system was motivated by the recognition that different features, events, and processes (referred to as FEPs in that project) have different origins and exhibit different characteristics; therefore, they should be treated differently. For example, the process system was to include all FEPs which either are active continuously, or are in a standby mode and will be activated by the occurrence of other externally driven causes. Only FEPs which represent the latter (i.e., externally driven causes) were considered in the development of alternative scenarios.

In 1989, the joint SKB/SKI scenario project held its first workshop, in which staff from both organizations as well as a number of international scenario experts participated. The attendees were asked to generate as comprehensive a list of FEPs as possible. The workshop participants were divided into four groups, and each group identified FEPs using a different classification scheme: 
- Likelihood of occurrence: likely, unlikely but possible, very unlikely

- Disposal system component: near field, far field, biosphere

- Time of occurrence: 0 to $100 \mathrm{yr}, 100$ to $10^{4} \mathrm{yr}, 10^{4}$ to $10^{6} \mathrm{yr},>10^{6} \mathrm{yr}$

- Cause: naturally induced, repository-induced, human-induced

The four lists of FEPs were combined into a single list. To document the rationale for each FEP, the experts were required to prepare a written note or comment outlining the definition, cause, possible consequence, and reason for inclusion for each FEP. References supporting the experts' assertions for each FEP were also provided. This information was assembled and stored in a computerized database for easy retrieval and revision. A total of 156 FEPs were identified at that workshop.

A smaller working group consisting primarily of SKB/SKI staff implemented the next step in the NRC/SNL methodology-screening of FEPs. A given FEP was screened out for one of three reasons:

(i) It was considered to be insignificant

(ii) It was assigned to the Process System

(iii) It was combined with one or more other FEPs

Figure 3-1 (Swedish Nuclear Power Inspectorate, 1991) shows the approach used to screen the FEPs. At the conclusion of the screening, each FEP was assigned to one of four classes:

- Class 1: the FEP, either individually or in combination, should be considered in the development of alternative scenarios because it is a primary external cause for the alteration of the disposal-system behavior.

- Class 2: the FEP belongs to the process system because it represents a phenomenon which either is continuously active or can be activated by the occurrence of Class 1 FEPs.

- Class 3: the FEP (e.g., human action leading to waste retrieval and mining, post-closure monitoring, etc.) needs to be considered differently from other FEPs (e.g., transport in groundwater system, climate, change, etc.).

- Class 4: the FEP is not significant and can, therefore, be screened out and eliminated from further consideration.

A FEP was considered to be insignificant if it met one or more of the following criteria:

- Low probability of occurrence $\left(<10^{-8} / \mathrm{yr}\right)$

- Negligible consequence

- Physically unreasonable 


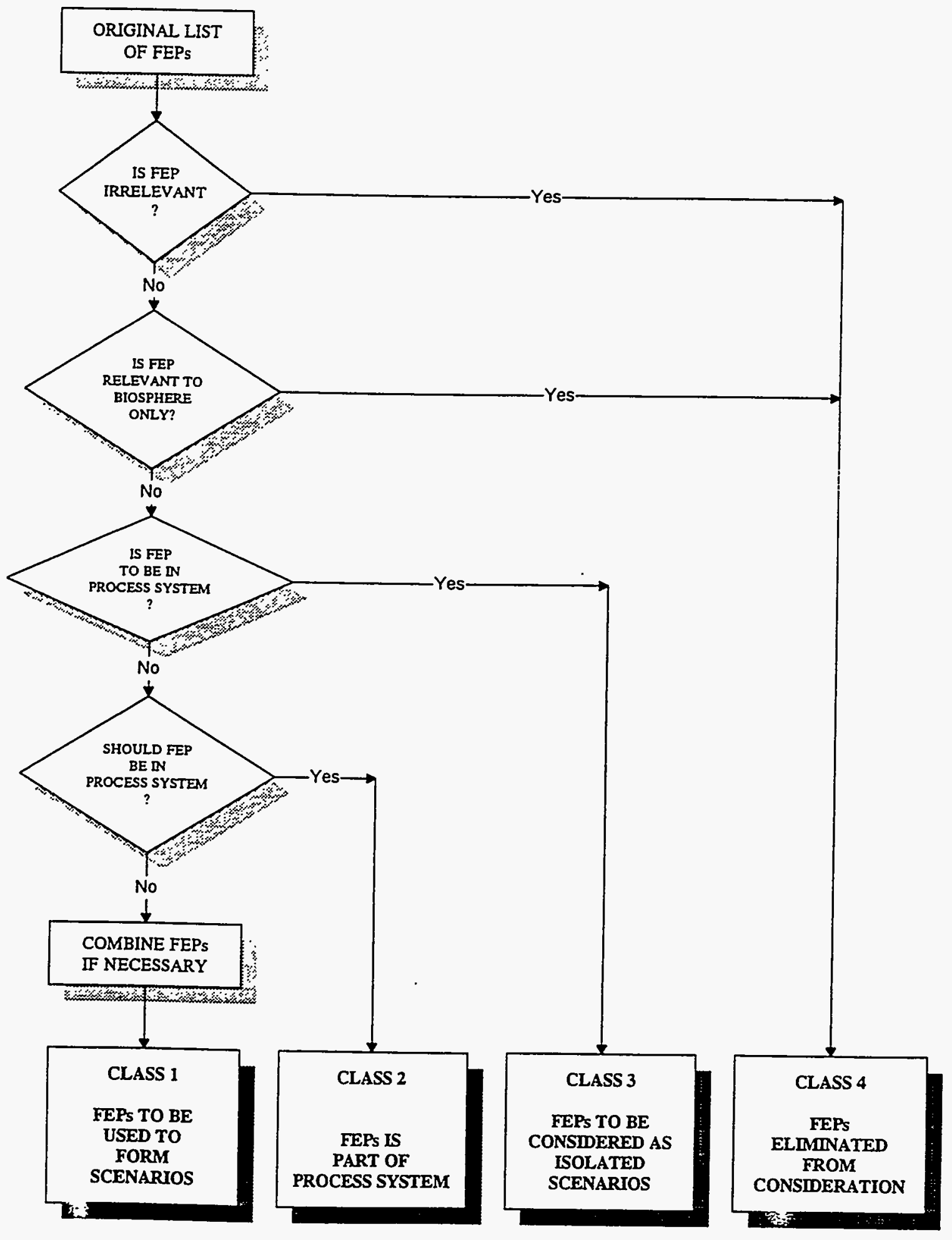

Figure 3-1. Schematic of Swedish FEP screening approach (after Swedish Nuclear Power Inspectorate, 1991) 
- Responsibility of future generations

- Management (e.g., double entry, poorly defined, lack of data, outside scope of PA such as a FEP acting on the biosphere which was not considered in the study, etc.)

Using these criteria, the number of FEPs in the original list was reduced to 123 . The lack of physical reasonableness was the most widely used screening criterion. With few exceptions (e.g., occurrence of meteorites), screening FEPs based on a low probability seemed to have been a difficult task, due mainly to a paucity of data and other relevant information.

After screening out the FEPs deemed not to be significant, the surviving ones were examined for possible inclusion in the process system. In addition to the conditions mentioned earlier for inclusion in the process system, the state of knowledge regarding a FEP needed to be sufficiently mature to allow for its simulation with some confidence. That is, a FEP, the behavior of which could not be simulated due to lack of data or information, would not be included in the process system. However, a review of the documentation on the application of this methodology (Swedish Nuclear Power Inspectorate, 1991) did not reveal if the lack of data was actually used in eliminating FEPs from the process system.

In order to further reduce the possible number of alternative scenarios, the FEPs which belonged to Class 1 were examined to decide whether two or more could be combined into a single FEP. Criteria used to combine FEPs included similar characteristics and consequences, and similar external causes, among others.

Lastly, a number of FEPs were determined to belong to a special class, Class 3, and these were not considered in the formulation of conventional scenarios as the FEPs which were assigned to Class 1 . These special FEPs were used to form isolated scenarios because their consequences will not be due to radionuclide releases through the groundwater flow and radionuclide transport system. Human actions which result in direct exhumation of the waste is an example of a FEP in this special class.

The result of the screening step was still a relatively large number of FEPs in Class 1, referred to as Kept FEPs to be combined to arrive at a set of scenarios. The initial joint SKB/SKI scenario exercise did not proceed further than the screening step. For the PA calculations in Project-90, SKI re-evaluated the list of Kept FEPs to arrive at "Scenario Cases" for the calculations (Swedish Nuclear Power Inspectorate, 1991). Project-90 was set up by SKI in 1986 to develop the PA capability it needs to evaluate a license application for a HLW repository by SKB around the year 2,000.

\subsection{UK Nirex Ltd. SCENARIO SELECTION APPROACH}

UK Nirex Ltd. is the entity in the UK responsible for the development and submission of a license application for the deep geologic disposal of low-level and intermediate-level waste, whereas the UK Department of the Environment is the regulatory authority responsible for the evaluation and granting (or rejection) of the license. As aforementioned and as will be discussed in the following, the latter advocates the use of the ESA as the method to deal with uncertainty in the future state of the disposal system. UK Nirex Ltd., however, has emphasized the use of scenarios arrived at using a top-down approach (Billington et al., 1990; Nuclear Energy Agency, 1992). 
The NRC/SNL scenario approach, as well as those implemented in Canada and Sweden, rely on a bottoms-up approach to construct the scenarios. That is, these approaches start by generating a comprehensive list of events and processes which can affect the performance of the disposal system and proceed to construct a manageable set of scenarios using an event-tree procedure. In contrast, the top-down approach starts, for example, by postulating unacceptable consequences from the deep disposal of radioactive wastes and seeks to identify the causes which can lead to those consequences by applying a fault-tree type approach.

The UK Nirex Ltd. scenario approach can be summarized as follows (Billington et al., 1990; Nuclear Energy Agency, 1992):

(i) Divide the disposal system into different components called Scenario Elements.

(ii) Construct an influence diagram which describes the interdependence between the different scenario elements.

(iii) Postulate a comprehensive set of alternative states which each scenario element could attain as it evolves during the regulatory period.

(iv) Form a Scenario Element State Tree to arrive at different combinations of states, each combination defining a potential scenario.

(v) Screen the combinations of scenario element states using well-defined criteria.

(vi) Estimate scenario probabilities by: (a) assigning subjective probabilities denoting Degrees of Belief to each scenario state; (b) taking into account the interdependencies among scenario elements indicated by the influence diagram to arrive at conditional probabilities for the scenario states; and (c) combining the probabilities of the states which constitute a given scenario.

Scenario elements can be defined using a variety of classification schemes, such as cause (natural phenomena, repository effects, human actions); disposal system component affected (repository, near field, far field, biosphere); etc.

UK Nirex Ltd. argues that the top-down approach avoids some of the difficulties associated with the bottoms-up approach when it comes to the assignment of the probability of occurrence. As long as the set of alternative states is comprehensive, the top-down approach leads to a smaller, more tractable number of scenarios than the bottoms-up approach.

Figure 3-2 shows the final five scenario elements used in a trial application of the UK Nirex Ltd. approach. Initially in this application, 40 possible scenario elements were identified. An influence diagram was then constructed and this led to the screening of most scenario elements. The influence diagram was assumed to represent probability conditioning; that is, the probability of a given state is conditional on the probability of another state. This approach allowed the screening of scenario elements on the basis that either the influence of one state on another was insignificant or the influence was very strong and was deemed to be a direct correlation. In other words, in some cases, the correlation between two scenario elements, and, hence, between the states within those elements, was either practically zero or almost perfect. In the former case, the scenario elements were not considered further, whereas in the 


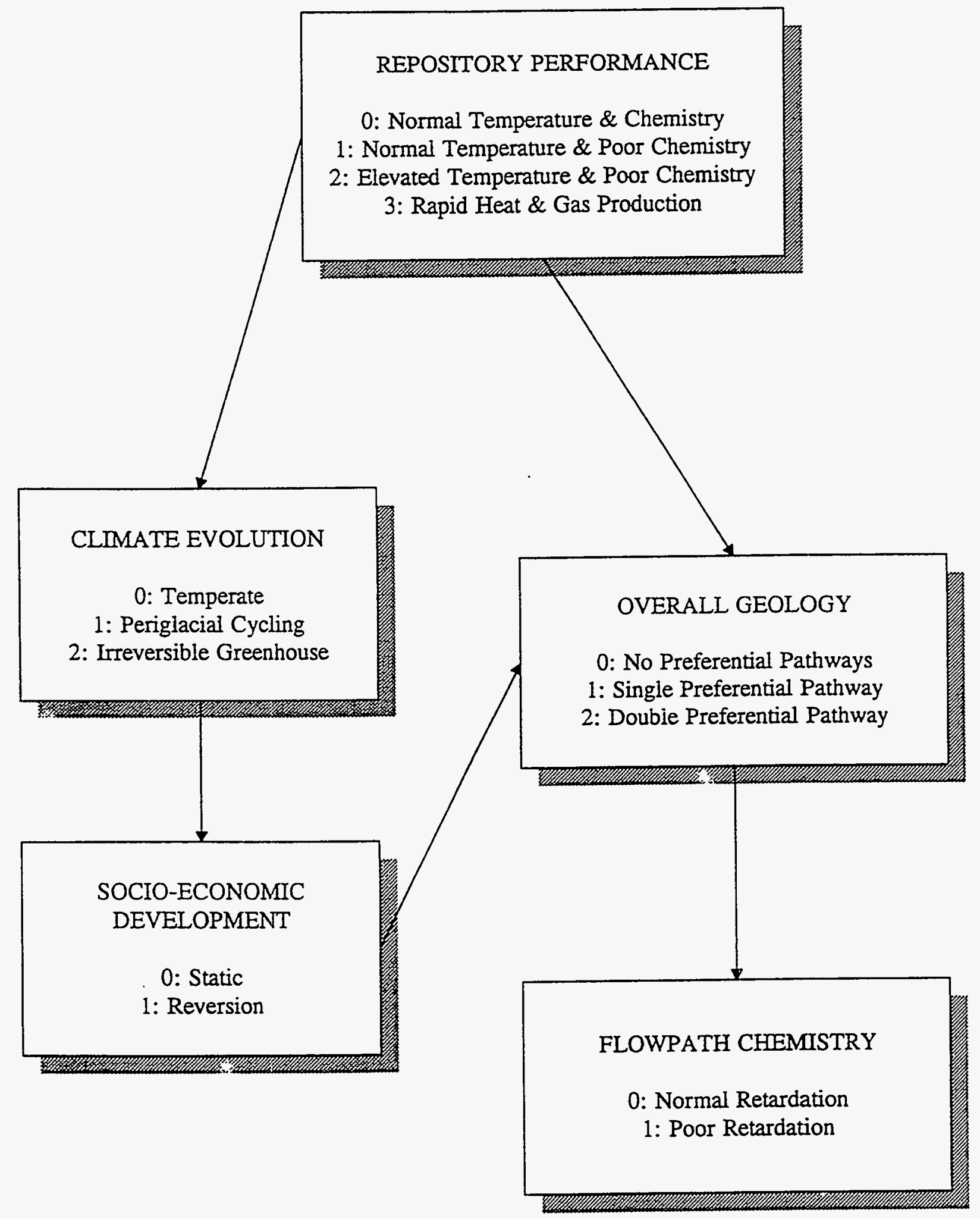

Figure 3-2. Final scenario elements in trial application of UK Nirex Ltd. topdown scenario selection approach (after Nuclear Energy Agency, 1992) 
latter the two scenario elements were combined into a single one. After this procedure was completed, residual influences remained among the five surviving scenario elements. These residual influences are represented qualitatively by the arrows in Figure 3-2.

Within each element, several states were postulated; the state assigned the number " 0 " represents the base state in each element. The combination of the base states then constitutes what is conventionally referred to as a base-case scenario. Using expert judgment, probabilities of occurrence were assigned, which took into account the indicated dependencies. Six different experts provided individual probability encoding judgments with apparently fairly good agreement (Nuclear Energy Agency, 1992).

\subsection{SCENARIO SELECTION APPROACH IN FRANCE}

The Regles Fondamentale de Surete No. III-2-f (Fundamental Safety Regulation No. III-2-f, or RFS for short) was promulgated in 1991 by the Central Agency for the Safety of Nuclear Facilities of the French Ministry of International Trade and Industry (Raimbault et al., 1992). The RFS is France's main regulation governing the final disposal of radioactive wastes. Within OECD countries including the United States, the RFS seems to be the most prescriptive regulation regarding the conduct of a PA for a deep geologic repository. This regulation apparently specifies, in an appendix, a preliminary list of scenarios for consideration at each of France's candidate repository formations: granite, schist, clay, and bedded salt.

Following the guidelines contained in the RFS, ANDRA (France's National Agency for Radioactive Waste Management) has developed a program, which includes PA, to integrate all aspects of site selection; repository design, construction, and operation; and safety demonstration. The RFS prescribes the general framework for the safety demonstration, and within that framework, for the selection of scenarios. According to Raimbault et al. (1992), it states the following.

The safety demonstration is based on deterministic evaluations of the radiological impact for two types of situations:

(i) A reference situation which corresponds to the occurrence of very probable or certain events

(ii) Hypothetical situations corresponding to occurrence of low probability events which may lead to preferential transfers

The RFS further specifies that the PA must include "evaluation of the individual exposures corresponding to a limited number of representative situations of the different family of events or sequences of events such that they correspond to the highest consequences" (Raimbault et al., 1992). Based on these guidelines, ANDRA's scenario selection approach consists of four steps (Raimbault et al., 1992):

(i) Identification of a complete set of initiating and independent events naturally, repository-, or humanly-induced which can affect the behavior of the repository 
(ii) Ranking of events based on probability, consequence, or relevance to a given formation or location

(iii) Identification of secondary events and/or processes caused by the initiating events

(iv) Definitions of families of scenarios and selection of the scenario potentially having the worst consequence from each family (called the Envelope Scenario )

The envelope scenario is used in the consequence analysis of the PA.

Following recommendations from the NEA's Scenario Working Group (Nuclear Energy Agency, 1992), selected scenarios are to be classified as either a normal evolution scenario or altered evolution scenarios. The former includes all events, processes, and phenomena expected to occur within the $10^{4}$-yr regulatory period specified in the RFS, whereas the latter consists of all those low-probability events, processes, and phenomena which cannot be discarded. By definition, the normal evolution scenario has a probability of occurrence of close to unity. 


\section{ENVIRONMENTAL SIMULATION APPROACH}

Since 1988, motivated primarily by a presentation by Thompson (1988) to the NEA Performance Assessment Advisory Group, there has been a great deal of attention paid to the ESA within the waste management community. Thompson's main argument centered around two assertions: (i) environmental changes, their sequence, and their duration need to be explicitly considered in PA of radioactive waste disposal facilities; and (ii) limitations of the scenario approach do not allow capturing the major effects of environmental changes, thus resulting in lower risk estimates.

Even though, as aforementioned, the debate on the need and value of the ESA has gained momentum in recent years, the application of models and computer codes based on this approach is not as recent. In the early 1980s, Pacific Northwest Laboratories developed the Geological Simulation Model (GSM) to conduct Monte Carlo simulation of continuous natural processes and initiating events in the Columbia Plateau in the northwestern United States (Petrie et al., 1982; Foley et al., 1982). Shortly thereafter, Intera (1983) extended the GSM to be non-site-specific and to consider a larger number of events and processes (e.g., climate change, glaciation, folding, diaparism, magmatic events, faulting, regional deformation, dissolution fronts, breccia pipes, etc.) and developed the Far-Field State Model (FFSM). However, to date, neither GSM nor FFSM has been applied in a total system performance assessment. More recently, the French Bureau of Geological and Mineral Research, in conjunction with the Commission of European Communities (CEC), developed the CASTOR computer code to simultaneously consider the effects of climatic change and tectonics on the evolution of the geohydrological system at a particular site or region (Nuclear Energy Agency, 1992). CASTOR was exercised by modeling the Paris region to predict the evolution of the basin over the last $100,000 \mathrm{yr}$ of the Quaternary using geological observations. The code failed to predict local tectonic effects using its global tectonic submodel (Nuclear Energy Agency, 1992).

\subsection{UNITED KINGDOM DEPARTMENT OF ENVIRONMENT'S ENVIRONMENTAL SIMULATION APPROACH}

Based on Thompson's (1988) arguments, the UK Department of Environment, Her Majesty's Inspectorate of Pollution (HMIP) undertook a research program to integrate environmental simulation into a total system performance assessment for the geologic disposal of radioactive waste. The environmental simulation was the centerpiece of the Dry Run 3 exercise sponsored and managed by HMIP (Sumerling, 1992). To date, this seems to be the only comprehensive PA study in which the ESA has been applied.

The components of the methodology developed by the HMIP and executed in the Dry Run 3 exercise is shown in Figure 4-1, and consists of two main steps (Sumerling, 1992):

(i) Generation of possible future evolutions of the natural environment using the TIME4 computer code

(ii) Prediction of the effects of the temporal changes represented by each climate evolution of the environment on releases from the repository, transport of radionuclides through the geosphere and the biosphere, and consequences in terms of radiological risk using the VANDAL computer code 


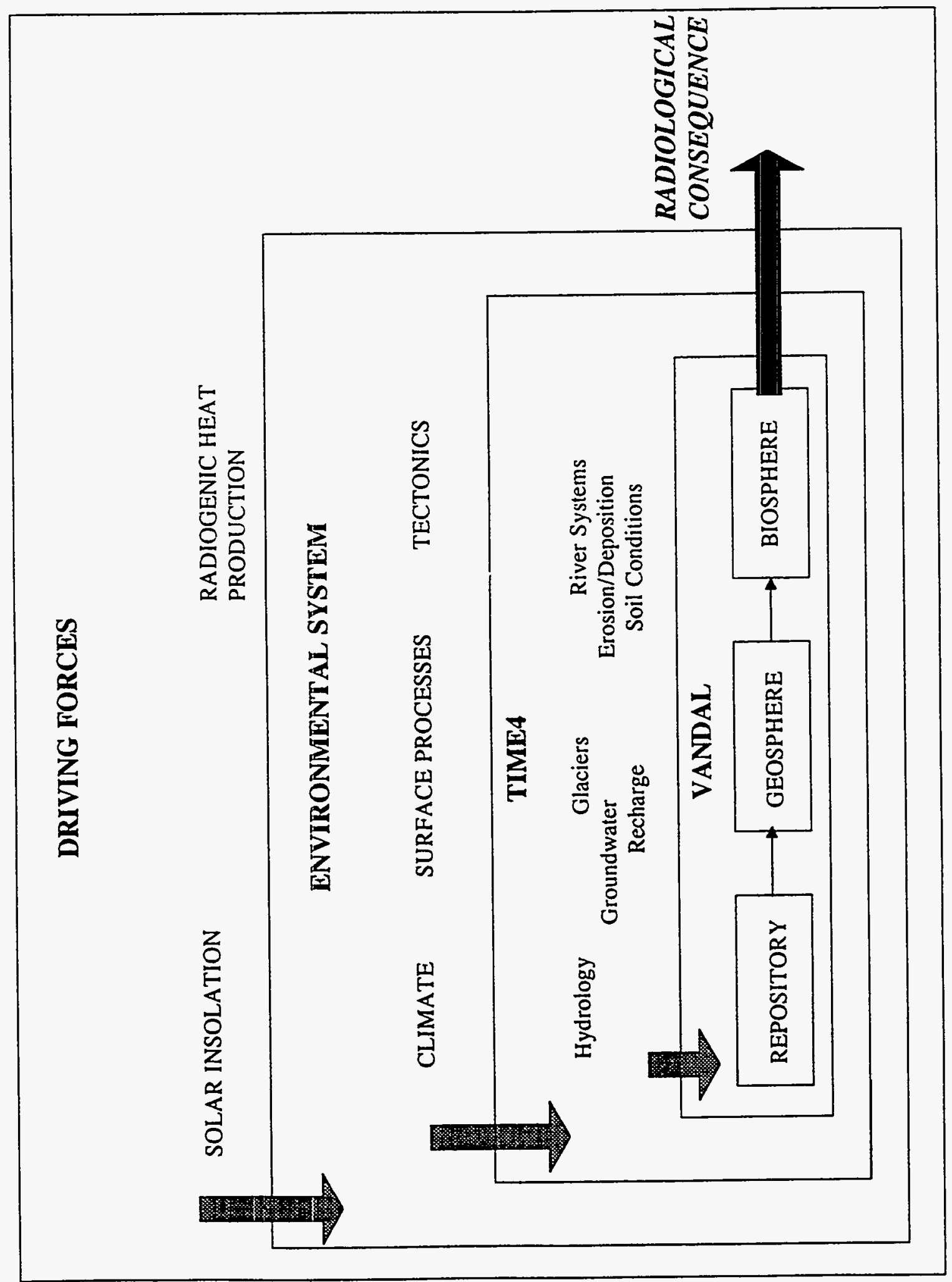

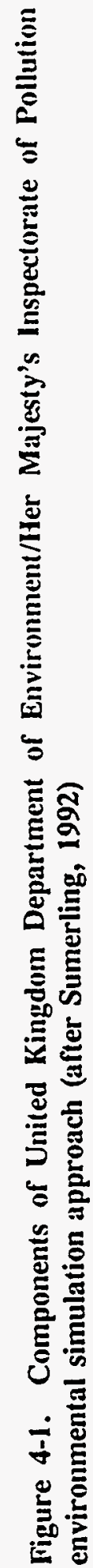


The fundamental premise of the HMIP ESA is based on the following assertions about the climate evolution and its effect on attendant processes at a waste disposal site (Boulton, 1990):

- Reconstruction of the dominant amplitudes and frequencies of global climate change over the last 3 million yr is possible

- Long-term stability of the natural climate system provides a degree of predictability for future climate based on extrapolation of the past

- Long-term oceanic records of global change, examined in conjunction with brief terrestrial records, provide a means to translate global climate changes into regional and local climate records

- Regional and local climate records combined with evidence from sediments allow the correlation of climate at these scales to the characteristics and magnitudes of processes relevant to the performance of a radioactive waste repository

Boulton (1990) reconstructed a global climate record with a fairly constant periodicity $(\sim 100,000 \mathrm{yr})$ for the last $750,000 \mathrm{yr}$. This record was used to derive the Markov transitional probabilities required to execute the model imbedded in the TIME4 computer code.

TIME4 is an extension of the TIME2 computer code, that is based on the FFSM developed by Intera (1983). TIME2 was developed to simulate a deterministic sequence of future climate states from the present to the next glaciation in Great Britain at shallow-land disposal sites (Ringrose et al., 1990). The duration and behavior of the environmental system within each climate state is considered to be uncertain, and the uncertainties are addressed using statistical sampling and Monte Carlo simulation. For each climate state, probability distribution functions (PDFs) for temperature and precipitation are derived from data covering about $30 \mathrm{yr}$ of measurements for analog climates in different parts of the world. These data are assumed to represent the spatial and temporal variability of the climate within each state. The processes modeled in TIME2 include (Ringrose et al., 1990):

- Precipitation and its distribution between surface water and groundwater recharge

- Sea level changes associated with the growth of ice sheets and greenhouse warming

- Nearby ice sheet growth and the effect of tilting and formation of ice-dammed lakes

- River processes including the effects of denudation of the land surface

- Occurrence of human intrusion into the repository

TIME4 retains many of the modeling capabilities of TIME2; some were extended to render TIME4 applicable to (Ringrose et al., 1990):

- Deep geologic disposal sites

- Several successive glacial periods over 1 million yr 
- Stochastic modeling of future sequences of climate states by using Markov transition probabilities to generate random samples of future sequences

- Transition probabilities and PDFs generated from a reconstructed climate record for the last $750,000 \mathrm{yr}$

At the end of each time step in TIME4, a new climate state is assumed to occur; typical time steps vary from 1,000 to $50,000 \mathrm{yr}$. The output for TIME4 is a set of time sequences of the boundary conditions influencing groundwater flow and radionuclide transport at the disposal site, such as topographic levels, sea levels, recharge, glacial ice-sheet location, and surface hydrology, and their associated probabilities.

This information serves as input to the VANDAL computer code (Laurens et al., 1990) which combines it with statistically sampled flow and transport parameters to generate time-dependent estimates of dose. VANDAL uses a network of one-dimensional (1D) legs to approximate the flow and transport system. It estimates releases from multiple sources into a multi-compartment biosphere model which, in turn, estimates dose to man. Every new climate state generated by TIME4 corresponds to a new set of boundary conditions and a recalculation of the groundwater flow field in VANDAL. Each flow field is used to solve the transport equations in each of the active legs of the network using the concentrations from the previous climate state as the initial conditions. VANDAL uses a multiple steady-state approach to simulate the transition of the environment from one climate state to the next.

At the request of the HMIP, an independent peer review was undertaken of the application of the ESA in Dry Run 3 (Zimmerman et al., 1992). The review indicated that, compared to the scenario approach, the consideration of different sequences of environmental change in the ESA can result in different estimates. However, the reviewers concluded that earlier assertions by Thompson (1988) regarding the ability of the ESA to overcome the limitations of the scenario approach could not be supported by the results of Dry Run 3. The reviewers' conclusion was based on several findings. First, the network used to simulate the groundwater flow system was not consistent with the time-dependent response of the repository system to environmental changes the ESA attempts to capture. The use of a fixed network of one-dimensional legs for all climate states may have artificially predetermine the range of possible solutions under the different climate states. Second, the reviewers felt that stating that the ESA leads to higher risk estimates than the scenario approach was not appropriate. The reviewers found that the higher values of risk estimated in the ESA could have been an artifact of the modeling approach used for groundwater flow and transport. The use of a fixed network for flow and a multiple steady-state method for transport may have caused sudden discharges of radionuclides to the biosphere as the system change from one climate state to another. The sudden discharges, necessary to comply with mass balance requirements, could have caused higher discharge than if the system would have been allowed to equilibrate after a climate-state change. Third, the comparison to the scenario approach in Dry Run 3 was not adequate. The team that carried out Dry Run 3 apparently was not sufficiently familiar with the scenario approach, and therefore, made several erroneous assumptions regarding the latter. For example, the most fundamental of these assumptions was that the scenario approach is equivalent to constant temperate conditions. Using the concept of scenario classes espoused by the NRC in the IPA exercises, the set of climate states used in Dry Run 3 would have been a scenario class and each of the sequences of climate states analyzed would have been a scenario belonging to that class. The reviewers felt that, should the HMIP team had used such an approach for the treatment of scenarios, the comparison between the ESA and the scenario approach would have been more relevant. The reviewers also stated that, until a comparison is carried out in which the capabilities of both approaches are exploited to the maximum, 
assertions regarding the superiority of one approach over the other are unwarranted. Fourth, the implementation of the ESA requires the use of subjective judgments to, at least, the same extent as the scenario approach; the NEA Scenario Working Group reached a similar conclusion (see next paragraph). It is noted that one of the original criticisms that Thompson levied against the scenario approach was its heavy reliance on such judgments.

The NEA Scenario Working Group (Nuclear Energy Agency, 1992), during its deliberations, had extensive discussions about the similarities and differences between the ESA and scenario approach. The group concluded that there are more similarities than differences, and that in many instances the latter seem to be due to differences in semantics rather than real differences. The group also concluded that the two approaches should not be viewed as one being an alternative to the other; rather, the group recommended that they be considered to be complementary. Scenario development and consequence analysis are likely to benefit significantly from advances in environmental simulation techniques, and that the scenario approaches provide the framework for the systematic identification and selection of precesses, events, and phenomena to be included in the ESA.

The group also stressed the fact that, to date, the ESA has only been able to model climate changes, and that other events and processes that can affect the long-term performance of the repository system still have to be addressed using the conventional scenario approach. However, it is fair to note that Woo (1992) recently proposed a method for the incorporation of human actions in the ESA. Woo's approach is based on the use of a Markov model, as opposed to more traditional Possion model, for the consideration of human actions. Woo postulates several states of knowledge about the repository that will affect the rate of human intrusion. Transitional probabilities are then used to shift from one state of knowledge to another. Similar to that manner in which the ESA handles changes in climate states, in Woo's model the transitional probabilities are used in the ESA to decide when to shift from one state of knowledge to the next in a postulated sequence. No attempt, to the authors' knowledge, has been made to implement Woo's approach in a PA. 


\section{OPEN ISSUES IN SCENARIO SELECTION}

There are a number of key issues which still remain open regarding the selection of scenarios and the analysis of their consequences in PAs of deep HLW repositories. Among the most salient ones are: (i) the role and use of expert judgments; (ii) the alternative interpretations and/or conceptualizations for estimating the consequences of different scenarios; and (iii) lack of uniqueness in scenario selection approaches and the reconciliation of results from different approaches, demonstration of completeness, and treatment of human intrusion scenarios.

\subsection{ROLE OF EXPERT JUDGMENTS}

The selection of scenarios, for the most part if not entirely, will depend on the use of expert judgments. Every example presented in this report, whether within the NRC HLW program, the DOE programs, or programs in other countries, has cited the extensive, and in some cases the exclusive, use of expert judgments in scenario selection. In some cases, the expert judgments have been used in the context of a well-documented, structured scenario selection methodology, while in others they have not. In several applications, the judgments have been obtained using a fairly formal approach, and in others they seem to have been elicited in an ad hoc manner. In some cases, the judgments have been provided by only one individual, while yet in others, they have been obtained from one or more groups of experts. Whether or not expert judgments will be used is not an issue because the nature of the problem does not seem to allow for any other means to be applied to the selection of scenarios. Rather the issue is whether the expert judgments will be obtained and used with a formal, semi-formal, or ad hoc approach.

Many investigators within the international waste management community [see Nuclear Energy Agency (1992) and Gallegos and Bonano (1993) for summaries] agree that the treatment of uncertainty in the future state of a disposal system, whether by developing scenarios or by other approaches such as the ESA, is the underpinning of a PA. Therefore, it seems reasonable that, given: (i) the very important role of scenarios in the PA; (ii) the complexity of developing scenarios and assigning a likelihood or probability of occurrence; (iii) the lack of uniqueness in a method for developing scenarios; and (iv) the already extensive use of expert judgments in scenario selection, the judgments should be elicited and used following a formal and rigorous procedure approach.

Regardless of the method used (event trees, fault trees, logic trees, individual expert versus one or more groups of experts, etc.), a great deal of interpretation and subjectivity will permeate throughout every aspect of the selection of scenarios. Therefore, whatever the approach may be to arrive at the set of scenarios for PA, that approach should be logical, systematic, well-documented, and transparent to allow for it to be scrutinized in a manner such that those reviewing the approach and the results of its application can extract the foundation for the judgments. Bonano et al. (1990) describe approaches, procedures, and techniques for the elicitation and use of formal expert judgments in various aspects of PA, including scenario selection. Bonano et al. (1990), following the steps in the NRC/SNL scenario selection methodology, explain the role that expert judgments will play in each of those steps. They describe available techniques which could be employed to elicit judgments in each of those steps.

Since the report by Bonano et al. (1990), the literature on the elicitation of expert judgments has presented some new approaches and techniques; some examples of recent works are the report prepared by Cambridge Decision Analysts Ltd for the UK Department of Environment/HMIP (Cambridge 
Decision Analysts Ltd., 1992) and Cooke (1991). Of particular interest are techniques for the calibration of experts presented by Cooke (1991).

To a large extent, the credibility of an elicitation exercise will rely on the credibility of the expert(s) who are providing the judgments. Therefore, it is reasonable to say that the quality of the process used to select the experts will be the foundation of the elicitation in scenario selection. Given the subjective and, to many, speculative nature of scenario selection, the choice and acceptability of the experts becomes a central issue which undoubtedly will attract attention and receive critical scrutiny. Hora et al. (1991) and DeWispelare et al. (1993) describe two recent expert elicitation exercises associated with scenario selection and probability assignment for the WIPP and YM sites, respectively. Both of these noteworthy expert-elicitation exercises are summarized in Subsections 5.1.1 and 5.1.2.

\subsubsection{Expert Judgment Elicitation for Human Intrusion into the Waste Isolation Pilot Plant}

The SNL WIPP PA group conducted an expert judgment elicitation exercise to generate information which will result in identifying modes of inadvertent human intrusion into the WIPP and the likelihood of such intrusions (Hora et al., 1991). The purpose of the project was twofold:

(i) To provide a basis for the designs of appropriate mechanisms to deter human intrusion

(ii) To arrive at quantitative estimates of the likelihood of various types of human intrusion

The first one generated information to facilitate the design of markers to inform future generations of the existence and contents of the repository, while the second provided input to PA.

The exercise was conducted in three phases:

(i) Phase 1-Futures Panel

(ii) Phase 2-Markers Panel

(iii) Phase 3-Estimation of Effective Drilling Rates for PA

The results of Phases 1 and 2 were used in Phase 3 to arrive at the actual human intrusion rates utilized in the PA exercises.

Phase 1-Futures Panel. The purpose of this phase of the exercise was to arrive at the types and likelihood of intrusion which can be expected into the WIPP as a result of the evolution into future societies. Their deliberations led to the development of probability distributions for inadvertent human intrusion into the WIPP. The WIPP Project formed a Futures Panel which consisted of 16 experts evenly divided into four teams. Each team was multidisciplinary in nature because the forecasting of future societies by necessity requires that it be examined from as diverse a point of view as practically possible. The objective of each team was to develop alternative futures over the 10,000-yr regulatory time frame and, from these, determine plausible modes of intrusion and the associated likelihoods or probabilities. Each team was allowed to decide how to tackle the problem and, as a result, arrived at different 
alternative futures. For the purpose of this discussion, the teams are referred to in generic terms as Team I, Team II, and so on.

Team I examined future civilizations in two ways:

(i) A top-down approach in which intrusive activities were first identified followed by the specific attributes of society which would lead to such activities. This resulted in some very broad, generic alternative futures.

(ii) Development of detailed futures using a bottoms-up approach.

The top-down approach was as follows:

- Identify the vulnerability of the WIPP

- Identify events which would be required to exploit the vulnerability

- Identify activities which could lead to the occurrence of the events

- Analyze societal and other conditions needed for the activities to take place.

This team also examined characteristics which will render the intrusion inadvertent, and provided preliminary, qualitative probability estimates for activities and events leading to intrusion.

The development of the detailed futures was an imaginative process which led to the postulation of specific states of future societies. These futures, because of their high level of specificity, had very low probabilities.

Team II used a forward process to create different views of the future, with the result being generic alternative futures. To arrive at these futures, the team members considered the possible environmental changes and socioeconomic factors which will qualitatively impact human intrusion into the WIPP. Their assessment resulted in narrative futures along the following lines:

- Technological knowledge increases

- Technological knowledge decreases

- Initial decrease and subsequent increase in technological knowledge

- Altered political control of the area where the WIPP is located

- Stasis (i.e., political and technological stability)

Because of the generic nature of these futures, many more specific future states of society are plausible. The probability estimates this team arrived at were controlled by two factors-political control over the WIPP and technological developments. 
Team III developed alternative futures based on a relationship between resources and society. They considered the following factors:

- Continued population growth, but constant level of consumption of resources at today's rate

- Continued population growth accompanied by a massive increase in the rate of consumption of resources

- Erosion of conditions at and near the WIPP due to war or major political change

- Consumption of resources dramatically decreased due to no population growth and extensive recycling

This team considered the earth primarily as a source of materials and energy and not as a human habitat. They also were the only team of the Futures Panel which allowed for transition between the different alternatives at different points in time. That is, the futures were considered as snapshots in time rather than as mutually exclusive paths of society's evolution. They also factored in amnesia about WIPP and the inability to use existing information about the repository and its contents.

Team IV used a four-component model to arrive at alternative futures:

(i) State of society, both locally and worldwide

(ii) The cost of minerals and energy

(iii) Food supply and demand

(iv) Governance of the WIPP region

In each component of their model the following factors were considered: (i) level of awareness about nuclear waste; (ii) presence of potentially intrusive activity; and (iii) modes of inadvertent intrusion. They also accounted for potential levels of resource costs (higher costs resulting on greater exploitation and extraction of resources), climate changes which could alter the demand for subsurface water, and the ability of the government to retain control of the WIPP and preclude human intrusion. This team generated a large number of futures by combining the different levels associated with each of these factors.

The combined efforts of the four teams in the Futures Panel was a large number of potential modes of intrusion:

- Excavation (archeological, mineral, construction)

- Disposal/storage (underground injection, petroleum storage, radioactive waste)

- Tunneling (transportation, pipeline, mole mining)

- Drilling (hydrocarbons, water, research, and development) 
- Offsite activities (water impoundment, explosions, water-well field, etc.)

Phase 2-Markers Panel. A second panel of 13 experts was organized into two teams to examine markers for the WIPP site (Hora, 1992). Each of these teams considered the results from the Futures Panel in order to suggest alternatives for the design of a marker system and to assess the ability of that system to deter human intrusion. The latter was assessed based on two factors: (i) the survivability of the markers over an extended period of time; and (ii) the ability of intruders to find the markers and comprehend the message(s) these contain. The members of the markers panel estimated two probabilities: $\mathrm{p}_{1}$ being the probability that the markers survive and $\mathrm{p}_{2}$ the probability that potential intruders will comprehend the message(s) in a manner which will deter them from proceeding with the activities which will constitute intrusion. The probabilities were estimated at various points in time throughout the length of the regulatory period.

Phase 3-Probabilities for PA Calculations. Based on the guidance in 40 CFR 191, the WIPP PA Group concluded that the only mode of intrusion which needs to be considered in PA is drilling. Therefore, probabilities for the possible drilling modes were examined. Of the three possible drilling modes-drilling for mineral resources, water wells, and injection wells-the first (drilling for mineral resources) has been the only one considered so far in the WIPP PA exercises (Hora, 1992).

From the findings of the Futures Panel, a frequency of inadvertent human intrusion, $\lambda$, as a function of time was obtained. This frequency, called the raw drilling intensity, did not account for the deterrence of the marker system; therefore, it was modified to arrive at the effective drilling intensity using the probabilities estimated by the Markers Panel. The effective drilling intensity, $\lambda_{\text {eff }}=\lambda\left(1-p_{1} p_{2}\right)$, is the main parameter of a time-dependent Poisson process which characterized the time of intrusion into the WIPP, and is a parameter sampled in the Monte Carlo simulation used in the PA calculations (Sandia National Laboratories, 1993).

However, a problem encountered was the combination of the probabilities provided by the Futures Panel due to the use of different methodologies by the different teams in this panel. Two of the teams only estimated the probability of the first intrusion and ignored subsequent intrusions as either unlikely or irrelevant, whereas the other two teams assessed the probability of various intrusions over the 10,000 -yr regulatory period. The latter two teams concluded that boreholes for resource exploitation and extraction will not continue after 300-500 yr following closure of the repository. One of the teams in the markers panel provided consensus values of $p_{1}$ and $p_{2}$, whereas the other team provided values for each expert. To obtain values of $\lambda_{\text {eff }}$ usable for PA, a complex procedure had to be used within the Monte Carlo simulation (Hora, 1992). The basic steps in this procedure are as follows:

(i) Randomly select one of the Futures Panel teams

(ii) Randomly select a level of future technology development

(iii) Generate a random variable to determine the intrusion intensity from the probability distribution for drilling rates

(iv) Randomly select one of the Markers Panel teams, and the individual team member as necessary 
(v) For each time period, generate the two probabilities associated with the durability and effectiveness of the markers

(vi) Calculate $\lambda_{\text {eff }}$ for each time period

\subsubsection{Expert Judgment Elicitation for Future Climate at Yucca Mountain}

DeWispelare et al. (1993) describe a recently concluded expert judgment elicitation exercise conducted by the Center for Nuclear Waste Regulatory Analyses (CNWRA) designed to identify possible climate scenarios at the proposed HLW repository at YM and its vicinity, and to estimate the associated probability of occurrence. The objectives of the exercise were the following:

(i) Develop expertise about the expert-judgment elicitation process to assist in the review by the NRC of the DOE use of expert judgments and to assist the NRC in the development of guidance on the subject.

(ii) Examine both formal and informal approaches to the use of expert judgments, and investigate aggregation and consensus-building techniques with expert panels.

(iii) Establish an expert panel and apply elicitation techniques to obtain judgments regarding the characteristics and probabilities of climate scenarios at the Yucca Mountain, Nevada vicinity (YMNV).

(iv) Provide data and documentation for use in Phase 3 of the NRC IPA.

The centerpiece of the exercise was the elicitation of probability distributions from five experts for climate-related variables. The elicitation exercise consisted of five major steps:

(i) Pre-elicitation activities

(ii) Training of experts

(iii) Individual elicitation sessions

(iv) Aggregation of results

(v) Followup

Each of these steps is briefly summarized here.

Pre-elicitation activities. The four aforementioned objectives were defined and agreed to by the project managers at the NRC and the CNWRA. The elicitation team was recruited to include normative experts from the CNWRA and Southwest Research Institute (SwRI), as well as expert consultants. This team included normative experts with experience in decision theory, probability theory and encoding, and psychology, as well as generalists with climatology and overall HLW disposal expertise. Following a very carefully crafted expert-selection process, five climate specialists were selected to provide the judgments. 
An issue statement on the specific purpose of the elicitation exercise was prepared. The statement dictated that:

- Future climate conditions at the YMNV were to be predicted

- The primary variables describing such climate conditions were annual precipitation, temperature, and changes in seasonal precipitation variability over $10,000 \mathrm{yr}$ after the present (AP)

PA generalists selected these primary variables as those potentially having the biggest impact on repository performance. The evaluation of the variables was to take place at the following time frames: $100,1,000,3,000,5,000,7,500$, and 10,000 yr AP. Later, as will be mentioned below, the climatology specialists requested that the 300 -yr time frame also be included. The specialists were to provide a probability distribution for each variable and climate control postulated to cause changes, if any, at each time frame.

Training and Issue Refinement. Prior to the actual elicitation sessions, an initial meeting was set up in which the members of the elicitation team and the specialists participated. During the meeting the specialists were oriented, the original issues statement was discussed and refined, and training on the conduct of the elicitation was offered. The CNWRA staff provided an overview of the HLW repository program and PA, the goals of the elicitation exercise, and a briefing on probability elicitation. The specialists examined the issue statements and suggested revisions, including the addition of the 300-yr time frame to the original list. The specialists generated a list of climate-forcing factors to be considered and agreed on a common set of assumptions.

The list of variables for which probabilities were to be elicited was:

- Precipitation

- Temperature

- Incident solar radiation

- Seasonal variability

- Precipitation impulse

- Short-term precipitation intensity

Individual Elicitations. The specialists were afforded 1 mo to review data, information, and/or model results they deemed appropriate and applicable to the problem. Each specialist prepared an independent paper describing his position on future climate scenarios at the YMNV. At a second group meeting, each specialist presented his paper for all experts to become familiar with each other's approach. The specialists were not allowed to challenge each other's position, and only questions of clarification were permitted.

During the individual elicitations, the elicitation team met with each specialist individually. Each session began with a brief discussion of the elicitation process. The specialist described the current 
climate controls at the YMNV. Two sets of judgments were elicited. The first set consisted of expected temperature and precipitation trends over $10,000 \mathrm{yr}$. These judgments served two purposes: (i) they provided the individual's fundamental approach to predicting climate; and (ii) they provided a basis for checking internal consistency of each expert's probabilities. The second set of judgments were the probability distributions for each of the selected variables at the specified time frames. The probability distributions were obtained either as probability distribution functions or cumulative distribution functions. The fractile method was used as the probability encoding technique. Each distribution was constructed from three to nine points depending on the level of precision with which each expert could propose the shape of the distribution. The reader is encouraged to consult the report by DeWispelare et al. (1993) for the specific distribution functions.

Aggregation of Individual Judgments. One of the purposes of this exercise was to examine different aggregation techniques, both mechanical and behavioral techniques, for combining the individual judgments of a group of experts. First, mechanical aggregation techniques were evaluated. The individual distribution functions were arithmetically averaged (i.e., all experts were assumed to be equally credible and assigned identical relative weights). This produced an average distribution for each variable at each time frame. The average distributions will be used as input to PA calculations.

Second, behavioral techniques were examined for two reasons: (i) to arrive at a consensus on probability distributions; and (ii) to arrive at consensus on the rationale regarding differences on underlying issues. Three separate behavioral aggregation evaluations for different distribution functions were attempted; each evaluation relied on different information. In the first evaluation, individual distribution functions for temperature at $100 \mathrm{yr}$ were considered. The specialists rather quickly agreed on a consensus distribution, but it differed from the mechanically aggregated one because one of the specialists capitulated his earlier position. Apparently, this specialist had become aware of new information which modified his earlier views. In the second evaluation, four different mechanically aggregated distributions for precipitation at 3,000 yr were presented. No consensus was possible because apparently the specialists were allowed to supplement the information originally provided with their own data. This led to different conclusions about the current conditions at the YMNV. The specialists agreed to three distribution functions which represented their original views with only some minor revisions. Modelers can use these three distributions by performing sensitivity analyses. The third evaluation consisted of examining individual and aggregated distributions for short-term intensity at 7,500 yr. No consensus distribution was possible; instead, three distributions were agreed to. In lieu of sensitivity analyses, modelers can select the lowest point in each of the three distributions, the median point in the middle distribution, and the highest point in the top distribution to arrive at a consensus distribution.

A structured discussion was arranged to explore possible aggregation on technical issues for which substantial disagreements between the specialists were identified. No consensus was reached because the specialists had little inclination to a modification of their beliefs and positions.

Elicitation Follow-Up. Within 30 days of the individual elicitations, the specialists were afforded the opportunity to review the results from the elicitations. In addition to the written notes, the elicitation sessions had been captured in videotape, and both provided a record of the sessions, the judgments provided, and the context in which the latter were provided. 


\subsubsection{Other Expert Judgment Issues}

discussing:

Four other issues related to the general elicitation and use of expert judgments are worth

- The calibration of experts

- The aggregation of expert judgments and use of multiple sources of information

- The balance between the level of rigor and the flexibility needed

- The choice between expert judgments and expert knowledge

\subsubsection{Calibration of Experts}

A major aspect in the identification and selection of experts is deciding what attributes an individual must exhibit to be so considered. Bonano et al. (1990) define an expert as an individual who is at the forefront of his/her discipline. Therefore, conventional wisdom suggests that an experienced individual with an extensive and distinguished dossier constitutes an expert. However, this may not always be the case; Cooke (1991) describes how both inexperienced and experienced experts can be calibrated in terms of objective knowledge on a given subject, which comes mainly from training and experience on the subject, and subjective knowledge, which reflects the degree of confidence with which an individual offers probability assessments. He points out that, depending on the specific problem at hand, one may or may not be able to distinguish between experienced and inexperienced individuals. Cooke discusses two experiments: one which dealt with a technical issue, in which the more experienced experts performed better than the less experienced ones, and another, dealing with a management issue, in which the result was the opposite (i.e., inexperienced individuals were better calibrated than experienced ones). While the subject of expert calibration still remains a difficult and rather ambiguous one, there are techniques which can be applied to enhance the credibility of the elicitation through the adequate calibration of the experts.

In principle, expert calibration is similar to model validation. If the expert are providing factual judgments (e.g., the numerical value of a model parameter), the user of the judgments could determine the goodness of the judgments by comparing the latter to known values of the variable(s) of interest. Unfortunately, for the long-term performance of a HLW repository, such is not the case. As a matter of fact, the reason for eliciting judgments is that the variable(s) is(are) not known and measuring its(their) value is precluded. Therefore, calibration of the experts-similar to model validation-is not possible in the strictest sense of the term. One possible approach for problems like the one of interest here is the use of so-called "seed or surrogate variables" (Cooke, 1991). In this case, the user of the judgments request the experts to provide estimates of the value of variables that only the user knows, and then the latter can measure how well the former perform. However, as with model validation, the issue is whether one can identify variables that would make could surrogates for a HLW repository system, for which there is no previous experience. 


\subsubsection{Aggregation of Expert Judgments}

When eliciting expert judgments from a group of experts to be used in PA of a HLW repository system, the judgments need to be aggregated in a manner that will allow their use in the PA. The studies conducted by Hora et al. (1991) and DeWispelare et al. (1993), described earlier in this section, clearly indicate the difficulties encountered when attempting to aggregate the judgments from multiple experts. Aggregation of expert judgments was particularly difficulty in the study by Hora et al. (1991) due to lack of a common basis for the aggregation because individual experts or groups experts used different methods to encode the probabilities. DeWispelare et al. (1993) attempted both analytical and behavioral methods to aggregate the judgments, and found that behavioral aggregation can be extremely difficult because the experts are unlikely to change their views in order to reach consensus.

One aggregation approach that does not present the aforementioned difficulties is the elicitation of judgments from the experts in group sessions; however, such an approach has come under much criticism because of the opportunity for strong personalities within the group to unjustifiably influence the outcomes of the elicitation (Merkhofer, 1987). Furthermore, such an approach limits the ability to examine the impact of the aggregation method on the results of the analysis and precludes the preservation of individual judgments (Raiffa, 1968). The latter is particularly important in dealing with regulatory issues, such as the licensing of a HLW repository.

The analytical aggregation approach used by DeWispelare et al. (1993) has become the most commonly used one (Cooke, 1991). Two basic assumptions underlie this approach: (i) the experts are independent and (ii) all experts are equally credible. Chhibber and Apostolakis (1993), however, claim that such an approach is encountering increased criticism and skepticism from the scientific community. They, instead, have proposed an approach based on a Bayesian model that allows the user of expert judgments to (i) assign relative weights to the different experts (i.e., assume that some experts are more credible than others) and (ii) account for interdependence between the experts. The application of the Bayesian model requires the value of several parameters (the standard deviation of the distribution function provided by the experts for a given variable, the expected bias for each expert, and the correlation between experts), and the user of the judgments must provide these values. The difficulty of coming up with the values for these parameters has been the reason why analytical aggregation approaches, to date, have not included such a level of sophistication. Chibber and Apostolakis attempt to provide some general guidance on how to assign values to the Bayesian model parameters.

\subsubsection{Level of Rigor in Expert Elicitation}

In general, there is a tendency for a formal elicitation of expert judgments to be very structured and rigid. This rigidity has both advantages and disadvantages for a PA. It can be advantageous in the sense that, when using more than one expert, the judgments are likely to all be expressed in a similar, if not identical, manner. This, in turn, should facilitate the aggregation and use of the results from the elicitation in the PA. However, it can also have disadvantages because too rigid an approach may stifle the way the different experts interpret and process information in order to capture important diversity of opinion. Conversely, lack of rigidity and structure in the approach may make it difficult to aggregate the results in a manner which will render them useful for the PA. The elicitation exercises documented by Hora et al. (1991) and DeWispelare et al. (1993) are good examples to illustrate this point. In the former, the lack of structure, which would have provided a common basis for the judgments expressed by the different groups of experts, resulted in a wide range of ideas about human intrusion. However, this same lack of structure precluded the aggregation of the results even with analytical or mechanical methods;

NUREG/CR-6351 $\quad 5-10$ 
instead, a very convoluted procedure had to be designed to arrive at probabilities of human intrusion for use in the PA. In the latter exercises (DeWispelare et al., 1993), a common basis ensures that the probability distributions for future climate at the YMNV could at least be mechanically aggregated in a more credible manner than in the human intrusion elicitation of Hora et al. (1991).

\subsubsection{Expert Judgments versus Expert Knowledge}

Due to the controversy which surrounds the use of expert judgments, there has been a recent push to focus elicitations on expert knowledge rather than on expert judgments ${ }^{4}$. The difference between expert knowledge and expert judgments, while subtle, is nonetheless fundamental. In the former (i.e., expert judgments), one elicits one or more experts' interpretation about information from other sources presented to them. For example, given the available body of information about likely future climate, experts are used to obtain the probability of climate change at a given repository site. The elicitation of expert knowledge, however, is concerned with obtaining the basic information from experts as opposed to obtaining it from the available literature. Expert knowledge is the underpinning for the development and application of expert systems. The elicitation and use of expert knowledge is not new; it is quite common in the medical sciences, particularly in arriving at medical diagnoses (e.g., see Goodwin and Wright, 1991). In the latter, medical students develop diagnostic skills, which tend to go beyond information contained in textbooks, from observing their professors in real medical situations during residence. It needs to be pointed out that expert knowledge primarily arises from past experiences; given this state of affairs, whether or not expert knowledge can be used to forecast the long-term behavior of a HLW repository is difficult to ascertain. Nevertheless, it is a new concept in risk assessment which may be worth exploring.

\subsection{ALTERNATIVE CONCEPTUAL MODELS}

Uncertainty in conceptual models typically results in the postulation of a set of alternative conceptualizations of the system (Gallegos and Bonano, 1993; Thompson and Sagar, 1993). In scenario selection and analysis, conceptual model uncertainty can arise from one of two sources: (i) different interpretations of the same set of data which results in different conceptualizations of the events, processes, and phenomena contained in a given scenario; and (ii) different conceptualizations of the processes and phenomena which can be activated by a given initiating event. Each type of conceptual model uncertainty could be addressed differently.

When alternative conceptual models arise from different interpretations of the effects (i.e., processes and phenomena) that an initiating event can cause, a different scenario should be associated with each interpretation. For example, the event-tree approach used by Barr and Dunn (1993) would result in a different path for each interpretation and, hence, a different scenario. In principle, each of the alternative scenarios will have a different probability of occurrence based on the relative likelihood of each interpretation. Chances are that collecting more data will not reduce the number of interpretations, and consequently, of scenarios.

On the other hand, when the alternative conceptual models arise from different interpretations of the same data regarding the manner in which the processes and phenomena in a given scenario should

John Garrick (Pickard, Lowe, and Garrick). Private Communication to E.J. Bonano (Beta Corporation International), November 17, 1993. 
be modeled, the situation is different. In principle, the number of alternative conceptual models could be reduced through data collection which will negate the validity of one or more assumptions in a given model. In practice, this could be difficult to accomplish. Apostolakis (1990) suggests that the likelihood of each conceptual model relative to the others can be estimated. In this case, the results obtained from the analysis of each conceptual model for a given scenario can be combined. However, whether such an approach is either practically achievable or even appropriate from a regulatory standpoint is an open issue, the resolution of which is critical. From a practical standpoint, the assignment of a relative likelihood to a conceptual model requires that the alternatives be statistically independent, a difficult attribute to demonstrate (Chhibber et al., 1991a; 1991b).

\subsection{HUMAN INTRUSION}

The consensus within the waste management community is that human intrusion, and the consequences thereof, should be considered in PA of radioactive waste disposal (Nuclear Energy Agency, 1989b). There also seems to be consensus on three issues associated with human intrusion:

(i) The likelihood of intrusion decreases with increased depth of the repository.

(ii) The likelihood of intrusion increases with time due to loss of knowledge about the existence and location of the repository.

(iii) The consideration of human intrusion will rely exclusively on subjective expert judgments.

However, that is where the consensus ends. No single framework for the systematic consideration of human intrusion has been adopted either nationally or internationally (Nuclear Energy Agency, 1989b). This could be problematic given the highly speculative and subjective nature of human intrusion.

How human intrusion should be considered in PA has generated much debate, unfortunately with little resolution of the issues. The range of issues extends from philosophical ones (the consideration of advertent versus inadvertent intrusion) to technical ones (the estimation of the probability of intrusion), to regulatory ones (the consideration of human intrusion in the same context as other disruptive events or scenarios in a PA). As opposed to the consideration of naturally occurring events, such as climatic and tectonic events for which empirical or mechanistic models may be used, the consideration of human intrusion involves forecasting human behavior, economic factors, and technology developments, none of which can be predicted with confidence.

It is believed that human intrusion into a waste repository can have a deleterious effect on the ability of the repository to isolate the wastes, and therefore, it should be an integral part of a safety or performance assessment (Grimwood and Smith, 1989; Grimwood and Thegerstrom, 1989; Nuclear Energy Agency, 1989b, 1993). The NRC, in 10 CFR Part 60, states that processes and events initiated by human activities other than ... (licensed) activities are to be unanticipated processes and events, and that the latter must be included in PAs designed to demonstrate/assess compliance with the regulatory requirements in $40 \mathrm{CFR}$ 191.13.

Some have argued that by maintaining active institutional controls, the likelihood of human intrusion can be greatly reduced. While there is truth to this statement, indefinite administrative or 
institutional controls cannot be relied upon as a measure to prevent human intrusion. As a matter of fact, most members of the international radioactive waste management community suggest that institutional controls should not be assumed to last more than 100 to 500 yr (Nuclear Energy Agency, 1993) following the closure of the repository. Furthermore, 40 CFR Part 191 specifically prescribes that credit for institutional controls shall not exceed $100 \mathrm{yr}$. Therefore, the modes and the likelihood of intrusion need to be postulated in order to consider human intrusion effects on the long-term performance of a repository. Once the mode and likelihood of intrusions are established, the associated consequences can be estimated.

The United States, in comparison to other countries, has one of the most prescriptive regulations regarding the consideration of human intrusion into both low-level radioactive waste and HLW disposal facilities. 10 CFR Part 61 not only specifically prescribes the consideration of human intrusion as a requirement, but also, to some extent, dictates the types of human intrusion scenarios which need to be considered, such as the Intruder-Construction, the Intruder-Discovery, and the Intruder-Agriculture scenarios. The EPA, in 40 CFR Part 191, of all national regulatory agencies, provides the most specificity regarding the treatment of human intrusion (Nuclear Energy Agency, 1989b). Appendix B of the 1985 version of 40 CFR Part 191 provides guidance regarding the assumptions which can be utilized in the estimation of the probability of intrusion. This guidance addresses only one human intrusion mode: drilling. Finally, 10 CFR 60.2 also provides guidance about human intrusion which is similar in nature to that in 40 CFR Part 191. It should be noted that changes regarding the consideration of human intrusion in 40 CFR Part 191, and possibly in 10 CFR Part 60, are likely as the EPA considers NAS recommendations for the revision of 40 CFR Part 191 for Yucca Mountain. As discussed in Chapter 1, the ENPA of 1992 requested that the NAS examine and provide recommendations to EPA regarding the latter's HLW regulation in three issues, one of which is the scientific defensibility of the estimation of the probability of human intrusion over $10,000 \mathrm{yr}$.

\subsubsection{Nuclear Energy Agency Human Intrusion Workshop}

In 1989, the NEA organized and held a workshop related to the estimation of the risk from human intrusion at waste disposal facilities (Nuclear Energy Agency, 1989b). The workshop had two purposes:

(i) To review general approaches for the assessment of human intrusion

(ii) To discuss scenario definitions, consequence modeling, and probability estimates for human intrusion

The general outcome of the workshop was that human intrusion should be part of the PA for it provides useful insight into the decision-making process. A key finding was that the consideration of human intrusion should play a major role in the siting process and in the development of waste acceptance criteria, particularly the specific types of waste which should be allowed to be disposed of at a given facility.

Another key finding of that NEA workshop was the consideration of human intrusion should be done with "moderation and balance" insofar as the level of sophistication with which one attempts to consider human intrusion is concerned. Participants, in general, were concerned that attempts to develop and implement too sophisticated an approach for the assessment of human intrusion could not be defended 
due to the paucity of data and, more importantly, the difficulty of forecasting human behavior far into the future. One problem pointed out was that attempts to cast human intrusion in a scientific context could undermine the credibility of the assessment, for one cannot predict with any degree of confidence the evolution of man and society and their uses for the subsurface and the resources therein contained.

The NEA workshop participants agreed, however, that the forecasting difficulties notwithstanding, the consideration of human intrusion in a structured manner could be very beneficial to illustrate the potential risks from human intrusion and their impact on repository performance. This information could be very useful primarily in the development of disposal practices which would tend to deter human intrusion.

In general, consideration of human intrusion shares the same three basic components of other scenarios resulting from naturally occurring events: (i) identification of initiating events and formulation of scenarios from these; (ii) estimation of the probability of occurrence; and (iii) estimation of the potential consequences. There is a wide range of human intrusion events and scenarios which can be envisaged, however, drilling is the most common one for deep geologic disposal. The NEA workshop participants cautioned that, while past and present human activities provide useful information about possible future activities, simple linear extrapolation should be avoided as a means of predicting the future. Factors such as technical, social, political, and economic developments could have both positive and negative influence on human behavior far into the future and these factors are impossible to predict.

One important point made was that human intrusion can have both immediate as well as long-term deleterious effects. While the emphasis in estimating the risk of intrusions is on the intruder(s), such intrusions could cause alterations to the groundwater system, the effects of which would not be evident immediately. The effects of the intrusion could manifest themselves in the intruder(s) in the shortterm and in long-term consequences at the end of the groundwater migration pathway.

The most difficult aspect in dealing with human intrusion is estimating the probability of intrusion. A surprising result was the apparent consistency in drilling rates reportedly being used in several different countries. There seemed to be a consensus that drilling rates or frequencies based on current data are about the only reliable pieces of information which, with caution, could be extrapolated into the future, as long as the assessment is kept simple and conservative.

Workshop participants expressed a higher degree of comfort with estimating consequences of human intrusion scenarios than with estimating their probability of occurrence. The open issues with consequence modeling of human intrusion scenarios are the same as with simulating other scenarios namely, uncertainty in the assumptions upon which the models are founded and in the numerical values of the parameters in the models.

\subsection{OTHER IMPORTANT ISSUES}

\subsubsection{Lack of Uniqueness in Scenario Selection Approaches}

A major issue which needs to be examined is the reconciliation of scenarios selected using different approaches. Many programs have adopted the NRC/SNL scenario selection methodology (Cranwell et al., 1990); however, this seems to have been more out of convenience than out of uniqueness. Having been the first scenario selection methodology proposed, many programs chose to use 
it as the point of departure for their site-specific assessments rather than develop a completely new approach.

Other programs, most notably the UK Nirex Ltd. and the United Kingdom HMIP, have chosen different approaches. Not only are these two approaches different from the NRC/SNL approach, but there are also fundamental differences between them. This is likely to present an interesting situation in the UK when Nirex submits a license application based on a PA which depends on a scenario approach and the HMIP evaluates it using a PA based on the ESA. Thompson (1988) proposed the ESA as an alternative which will overcome the limitations and shortcomings of the scenario approach. One of the conclusions of the HMIP's Dry Run 3 exercise is that the scenario approach underestimates risks. However, a review of that exercise (Zimmermann et al., 1992) revealed that the comparison between the ESA and the scenario approach had not considered all of the latter's capabilities and, therefore, the aforementioned conclusion may be premature. Zimmermann et al. (1992) suggest that, unless a well-designed comparison is performed, the similarities and differences between the scenario approach and the ESA cannot be elucidated, and that statements about the superiority of one approach over the other are not well founded. Cranwell et al. (1990) proposed a mathematical procedure to compare the two approaches based on the estimation of total risk, but the procedure is yet to be tested.

In the United States, the DOE has proposed a scenario selection approach for YM using generalized event trees (Barr and Dunn, 1993), the results of which supposedly can be mapped into the approach in the NRC/SNL scenario selection methodology. However, whether or not this will be possible in practice is yet to be determined. More important, is the apparent lack of consistency even within DOE programs (i.e., WIPP and YM) regarding the approach to select scenarios for PA.

Sweden seems to be the only country with a major radioactive waste management program where the proponent and regulator have agreed to jointly tackle the scenario selection process. While SKB and SKI will select scenarios independently, they have, if not necessarily agreed to, examined a common general framework to use in the selection of scenarios. Such an approach is likely to have big benefits during the licensing process, for the focus of the discussion will be comparisons of and rationale for the scenarios selected and not on the approach used to select them.

\subsubsection{Completeness of Scenarios}

The issue of completeness regarding the selection of scenarios is not new. Just about every publication related to uncertainty analysis in PA, in general, or to scenario selection, specifically, mentions completeness as an open issue and the need to deal with it in order to have a defensible PA. However, to date, no one single method has been proposed or developed to specifically deal with this issue. Bonano et al. (1990) have suggested some methods to be applied in expert judgment elicitations, but none have been tried and evaluated in the context of scenario selection. The NEA Scenario Working Group (Nuclear Energy Agency, 1992) suggested that, if one chooses a bottoms-up approach for scenario selection (such as the NRC/SNL methodology), a limited application of a top-down approach could be a check for completeness, and vice versa. Codell et al. (1992) mention that such a test may be used in the NRC's IPA exercises. 


\subsubsection{Probability of Occurrence}

Perhaps one of the most difficult issues associated with scenario selection is the estimation of a probability of occurrence. Many different approaches or techniques have been proposed, such as classical or frequentist probability estimation techniques, the use of probability models, stochastic modeling, and the use of expert judgments.

One of the most comprehensive studies on the issue was conducted for the NRC by SNL and documented in a two-volume report (Hunter and Mann, 1989; Apostolakis et al., 1991). In the first volume, a survey of different techniques for estimating probabilities associated with resource exploration (human intrusion), climate change, tectonics and seismicity, seismic hazard assessment, and volcanism is documented. The second volume demonstrates a methodology for estimating probabilities associated with climate change, tectonics, and human intrusion for the YM site. This methodology relies on the use of all available information; whether it is historical data, models results, or expert judgments. Bayes' Theorem provided the framework for combining all the information. Decision theory was also used to assist in the synthesis of the information and in the selection of alternatives. The main sources of information for estimating the probability of climate change were historical data and models; for tectonics were historical data, models, and expert judgments; and for human intrusion, sources were historical data and expert judgments.

Other recent studies pertaining to the estimation of the probability of occurrence of scenarios have already been discussed in this report: for example, the probability of human intrusion into the WIPP (Hora et al., 1991) and the probability of climate change at the YMNV (DeWispelare et al., 1993). Both of these studies relied exclusively on the use of expert judgments.

The WIPP Project, for example, has apparently adopted an approach for the generation of the CCDF required by the containment requirements in 40 CFR Part 191 based on the generation of a family of CCDFs (Sandia National Laboratories, 1993; Helton, 1993). The family of CCDFs is supposed to capture the wide range of possible values for the probability of occurrence of scenarios; in the WIPP case, the only scenario considered is human intrusion due to drilling into the repository. However, such an approach has its own drawbacks: the CCDFs range from some which are several orders of magnitude below of the EPA standard (the compliance zone) to others which are near the standard, to others which are above the standard (violation zone). Helton (1993) states that each CCDF in the family is equally probable and equally defensible. If one believes Helton's assertion-and there seems to be no reason to do otherwise-then no matter how many CCDFs in the family fall below the standard, the site will fail to comply because some CCDFs fall very close to or above the standard.

All these studies related to the estimation of the probability of occurrence notwithstanding, the subject still remains a very difficult one. The difficulty arises because of the following dichotomy. In principle, one would like the judgments to be based on abundant data about the repository system; however, it is the paucity of such data and the inability to collect them that necessitate the use of expert judgments. Therefore, the estimation of the probability of occurrence of scenarios and of the event and processes that comprise the scenarios still remains an elusive issue at this time. It is quite obvious that resolution of the issue is critical to the demonstration (DOE) and the determination (NRC) of compliance with the containment requirements in 40 CFR Part 191. 


\section{CONCLUDING REMARKS}

In this report, the scenario selection approaches used by the major national radioactive waste management programs in the United States and in other members countries of the OECD have been reviewed. An attempt has been made to highlight both similarities and differences among the approaches reviewed. Other approaches-namely, the ESA-have been proposed as alternative to the use of scenarios, and therefore, for completeness sake, the ESA has also been discussed. No one approach has been endorsed as being superior to the others.

In Chapter 5, some of the most salient issues related to the selection and use of scenarios in PA are summarized. It is clear that, independent of one's own personal opinion about the use of expert judgments, these play, and are expected to continue to play, a major role in both the selection of scenarios and the determination of their probability of occurrence. Several open issues were discussed, including the consideration of human intrusion and the completeness of the scenarios. In addition to these two open issues, two more critical ones which remain unresolved are the estimation of the probability of occurrence and the reconciliation of scenarios arrived at using different approaches.

Little progress seems to have been made by international activities examining the consideration of human intrusion. These activities, sponsored mainly by the NEA, seem to have either reiterated previous open issues or raised new ones about human intrusion. The highly speculative nature of forecasting human actions far into the future and the lack of a general approach to deal with human intrusion in PA still present great challenges.

The resolution of the estimation of the probability of occurrence of events and processes comprising scenarios remains a most critical issue. There seem to be many different schools of thought about how to estimate such probabilities and how to use them in a PA. It has been shown that the numerical value of the probability of occurrence could have a significant impact on the demonstration of compliance. Clearly, this indicates the need for comprehensive studies on this issue.

Finally, the different approaches to select scenarios, particularly between the DOE and the NRC, may end up being an important subject of discussion because it is not clear that direct comparisons between the results obtained with the different approaches are possible. While theoretically Barr and Dunn (1993) have claimed that the results can be compared, this is yet to be demonstrated in practice. More fundamentally, the validity of the claim made by those advocating the ESA about that approach's superiority to the scenario approach is yet to be examined. A detailed comparison between the different scenario approaches, and between the ESA and the scenario approach, seems warranted to elucidate some of these issues. 


\section{REFERENCES}

Arthur D. Little, Inc. 1980. Technical Support of Standards for High-Level Radioactive Waste Management, Volume D, Release Mechanisms. EPA 520/4-79-007D. Washington, DC: U.S. Environmental Protection Agency.

Andersson, J. and T. Eng. 1990. The joint SKI/SKB scenario development project. Safety Assessment of Radioactive Waste Repositories. Paris, France: Nuclear Energy Agency: Organization for Economic Cooperation and Development: 397-404.

Andersson, J., T. Carlsson, T. Eng, F. Kautsky, E. Soderman, and S. Wingefors. 1989. The Joint SKI/SKB Scenario Development Project. SKI Technical Report 89:14. Stockholm, Sweden: Swedish Nuclear Power Inspectorate.

Apostolakis, G. 1990. The concept of probability in safety assessments of technological systems. Science 250: 359-1364.

Apostolakis, G., R. Bras, L. Price, J. Valdes, K. Wahi, and E. Webb. 1991. Techniques for Determining Probabilities of Events and Processes Affecting the Performance of Geologic Repositories, Volume 2. NUREG/CR-3964, SAND86-0196. Washington, DC: Nuclear Regulatory Commission.

Barr, G.E. and E. Dunn. 1993. A working definition of scenario and a method of scenario construction. Proceedings of the Fourth Annual International Conference on High Level Radioactive Waste Management. La Grange Park, IL: American Nuclear Society: 1,093-1,098.

Barr, G.E., E. Dunn, H. Dockery, R. Barnard, G. Valentine, and B. Crowe. 1993. Scenarios Constructed for Basaltic Igneous Activity at Yucca Mountain and Vicinity. SAND91-1653. Albuquerque, NM: Sandia National Laboratories.

Billington, D.E., D.A. Lever, S.J. Wisbey. 1990. Radiological assessment of deep geological disposal: Work for UK Nirex Ltd. Safety Assessment of Radioactive Waste Repositories, Paris, France: Nuclear Energy Agency: Organization for Economic Cooperation and Development: 271-282.

Bingham, F.E., and G.E. Barr. 1979. Scenarios for Long-Term Release of Radionuclides from a NuclearWaste Repository in the Los Medanos Region of New Mexico. SAND78-1730. Albuquerque, NM: Sandia National Laboratories.

Bonano, E.J., P.A. Davis, L.R. Shipers, K.F. Brinster, W.E. Beyeler, C.D. Updegraff, E.R. Shepherd, L.M. Tilton, and K.K. Wahi. 1989. Demonstration of a Performance Assessment Methodology for High-Level Waste Disposal in Basalt Formations. NUREG/CR-4759, SAND86-2325. Washington, DC: Nuclear Regulatory Commission.

Bonano, E.J., and K.K. Wahi. 1990. Use of Performance Assessment in Assessing Compliance with the Containment Requirements in 40 CFR Part 191. NUREG/CR-5521, SAND 90-0127. Washington, DC: Nuclear Regulatory Commission. 
Bonano, E.J., S.C. Hora, R.L. Keeney, and D. von Winterfeldt. 1990. Elicitation and Use of Expert Judgment in Performance Assessment for High-Level Radioactive Waste Repositories. NUREG/CR-5411, SAND89-1821. Washington, DC: Nuclear Regulatory Commission.

Boulton, G.S. 1990. Time-dependent modelling of environmental change: The effect of quaternary glaciation. Safety Assessment of Radioactive Waste Repositories. Paris, France: Nuclear Energy Agency: Organization for Economic Cooperation and Development: 363-375.

Buxton, B.E. (ed.). 1989. Geostatistical, Sensitivity, and Uncertainty Methods for Ground-Water Flow and Radionuclide Transport Modeling. CONF-870971. Columbus, OH: Battelle Memorial Institute.

Cambridge Decision Analysts Ltd. 1992. Procedures for the Elicitation of Expert Judgments in the Probabilistic Risk Analysis of Radioactive Waste Repositories: An Overview. Cambridge, England, UK: Cambridge Decision Analysts Ltd.

Campbell, J.E., and R.M. Cranwell. 1988. Performance assessment of radioactive waste repositories. Science 239: 1,389-1,392.

Chhibber, S., and G. Apostolakis. 1993. Some approximations useful to the use of dependent information sources. Reliability Engineering and System Safety 42: 67-86.

Chhibber, S., G. Apostolakis, and D. Okrent. 1991a. On the quantification of model uncertainty. Proceedings of the International Conference on Probabilistic Safety Assessment and Management. London, England, UK: Elsevier Applied Science: 1,483-1,488.

Chhibber, S., G. Apostolakis, and D. Okrent. 1991b. A probabilistic framework for the analysis of model uncertainty. Trans. IChemE 69(B): 1-9.

Chhibber, S., G. Apostolakis, and D. Okrent. 1992. A taxonomy of issues related to the use of expert judgments in probabilistic safety studies. Reliability Engineering and System Safety 38: 27-45.

Clairborne, H.C., and F. Gera. 1974. Potential Containment Failure Mechanisms and Their Consequences at a Radioactive Waste Repository in Bedded Salt in New Mexico. ORNL-TM4639. Oak Ridge, TN: Oak Ridge National Laboratory.

Codell, R., N. Eisenberg, D. Fehringer, W. Ford, T. Margulies, T. McCartin, J. Park, and J. Randall. 1992. Initial Demonstration of the NRC's Capability to Conduct a Performance Assessment for a High-Level Waste Repository. NUREG-1327. Washington, DC: Nuclear Regulatory Commission.

Cooke, R.M. 1991. Experts in Uncertainty, Opinion and Subjective Probability in Science. New York, NY: Oxford University Press. 
Cranwell, R.M., J.E. Campbell, J.C. Helton, R.L. Iman, D.E. Longsine, N.R. Ortiz, G.E. Runkel, and M.J. Shortencarier. 1987. Risk Methodology for Geologic Disposal of Radioactive Waste: Final Report. NUREG/CR-2452, SAND81-2573. Washington, DC: Nuclear Regulatory Commission.

Cranwell, R.M., R.W. Guzowski, J.E. Campbell, and N.R. Ortiz. 1990. Risk Methodology for Geologic Disposal of Radioactive Waste: Scenario-Selection Procedure. NUREG/CR-1667, SAND80-1429. Washington, DC: Nuclear Regulatory Commission.

Davis, P.A., E.J. Bonano, K.K. Wahi, and L.L. Price. 1990. Uncertainties Associated with Performance Assessment of High-Level Radioactive Waste Repositories. NUREG/CR-5211, SAND88-2703. Washington, DC: Nuclear Regulatory Commission.

DeWispelare, A.R., L.T. Herren, R.T. Clemen, and M.P. Miklas. 1993. Expert Elicitation of Future Climate in the Yucca Mountain Region. CNWRA 93-016. San Antonio, TX: Center for Nuclear Waste Regulatory Analyses.

Foley, M.G., G.M. Petrie, A.J. Baldwin, and R.G. Craig. 1982. Geologic Simulation Model for a Hypothetical Site in the Columbia Plateau, Volume 2: Results. PNL-3542-2. Richland, WA: Pacific Northwest Laboratory.

Gallegos, D.P. 1991. A Performance Assessment Methodology for High-Level Radioactive Waste Disposal in Unsaturated, Fractured Tuff. NUREG/CR-5701, SAND91-0539. Washington, DC: Nuclear Regulatory Commission.

Gallegos, D.P., and E.J. Bonano. 1993. Consideration of uncertainty in the performance assessment of radioactive waste disposal from an international regulatory perspective. Reliability Engineering and System Safety 42: 111-123.

Goodwin, P., and G. Wright. 1991. Decision Analysis for Management Judgment. Chichester, West Sussex, England: John Wiley \& Sons.

Grimwood, P., and G. Smith. 1989. Human intrusion: Issues concerning its assessment. Risks Associated with Human Intrusion at Radioactive Waste Disposal Sites, Proceedings of an NEA Workshop. Paris, France: Nuclear Energy Agency/Organization for Economic Cooperation and Development.

Grimwood, P., and C. Thegerstrom. 1989. Assessment of the risks associated with human intrusion at radioactive waste disposal sites-some observations from an NEA workshop. Safety Assessment of Radioactive Waste Repositories: Paris Symposium. Paris, France: Nuclear Energy Agency/Organization for Economic Cooperation and Development.

Guzowski, R.V. 1990. Preliminary Identification of Scenarios that May Affect the Escape and Transport of Radionuclides from the Waste Isolation Pilot Plant, Southeastern New Mexico. SAND89-7149. Albuquerque, NM: Sandia National Laboratories. 
Guzowski, R.V. 1991. Evaluation of Applicability of Probability Techniques to Determining the Probability of Occurrence of Potentially Intrusive Events at the Waste Isolation Pilot Plant. SAND90-7100. Albuquerque, NM: Sandia National Laboratories.

Helton, J.C. 1993. Risk, uncertainty in risk, and the EPA release limits for radioactive waste disposal. Nuclear Technology 101: 18-38.

Hora, S.C. 1992. Probabilities of Human Intrusion into the WIPP Methodology for the 1992 Preliminary Comparison. Internal Report to Department 6342. Albuquerque, NM: Sandia National Laboratories.

Hora, S.C., D. von Winterfeldt, and K.M. Trauth. 1991. Expert Judgment on Inadvertent Human Intrusion into the Waste Isolation Pilot Plant. SAND90-3063. Albuquerque, NM: Sandia National Laboratories.

Hunter, R.L. 1983. Preliminary Scenarios for the Release of Radioactive Waste from a Hypothetical Repository in Basalt of the Columbia Plateau. NUREG/CR-3353, SAND83-1342. Washington, DC: Nuclear Regulatory Commission.

Hunter, R.L. 1989. Events and Processes for Constructing Scenarios for the Release of Transuranic Waste From the Waste Isolation Pilot Plant, Southeastern New Mexico. SAND89-2546. Albuquerque, NM: Sandia National Laboratories.

Hunter, R.L., and C.J. Mann (eds.). 1989. Techniques for Determining Probabilities of Events and Processes Affecting the Performance of Geologic Repositories, Vol. 1. NUREG/CR-3964, SAND86-0196. Washington, DC: Nuclear Regulatory Commission.

Hunter, R.L., G.E. Barr, and F.W. Bingham. 1982. Preliminary Scenarios for Consequence Assessments of Radioactive-Waste Repositories at the Nevada Test Site. SAND82-0426. Albuquerque, NM: Sandia National Laboratories.

Hunter, R.L., G.E. Barr, and F.W. Bingham. 1983. Scenarios for Consequence Assessments of Radioactive-Waste Repositories at Yucca Mountain, Nevada Test Site. SAND82-1277. Albuquerque, NM: Sandia National Laboratories.

International Atomic Energy Agency. 1983. Concepts and Examples of Safety Analysis for Radioactive Waste Repositories in Continental Geologic Formations, Safety Series No. 58. Vienna, Austria: International Atomic Energy Agency.

Intera. 1983. FFSM: Far-Field State Model. ONWI-436. Austin, TX: Intera Environmental Consultants, Inc.

Laurens, J.M., B.G.J. Thompson, and T.J. Sumerling. 1990. The development and application of an integrated radiological risk assessment procedure using time-dependent probabilistic risk analysis. Safety Assessment of Radioactive Waste Repositories. Paris, France: Nuclear Energy Agency: Organization for Economic Cooperation and Development: 627-638. 
Marietta, M.G., S.G. Bertram-Howery, D.R. Anderson, K.F. Brinster, R.V. Guzowski, H. Izzolino, and R.P. Rechard. 1989. Performance Assessment Methodology Demonstration: Methodology Development for Evaluating Compliance with EPA 40 CFR 191, Subpart B, for the WIPP. SAND89-2027. Albuquerque, NM: Sandia National Laboratories.

Merkhofer, M.W. 1987. Quantifying judgmental uncertainty; methodology, experiences and insights. IEEE Transactions on Systems, Man, and Cybernetics SMC-17: 741-752.

McGuire, R.K. (ed). 1990. Demonstration of Risk-Based Approach to High-Level Waste Repository Evaluation. EPRI NP-7057. Palo Alta, CA: Electric Power Research Institute.

McGuire, R.K. (ed.). 1993. Demonstration of Risk-Based Approach to High-Level Waste Repository Evaluation: Phase 2. EPRI TR-100384. Palo Alta, CA: Electric Power Research Institute.

Nuclear Energy Agency. 1987. Uncertainty Analysis for Performance Assessment of Radioactive Waste Disposal Systems. Paris, France: Nuclear Energy Agency: Organization for Economic Cooperation and Development.

Nuclear Energy Agency. 1989a. Safety Assessment of Radioactive Waste Repositories: Paris Symposium. Paris, France: Nuclear Energy Agency: Organization for Economic Cooperation and Development.

Nuclear Energy Agency. 1989b. Risk Associated with Human Intrusion at Radioactive Waste Disposal Sites. Paris, France: Nuclear Energy Agency: Organization for Economic Cooperation and Development.

Nuclear Energy Agency. 1992. Systematic Approaches to Scenario Development. Paris, France: Nuclear Energy Agency: Organization for Economic Cooperation and Development.

Nuclear Energy Agency. 1993. Future Human Actions at Radioactive Waste Disposal Sites, Draft Report. Paris, France: Nuclear Energy Agency: Organization for Economic Cooperation and Development.

Nuclear Regulatory Commission. 1983. Disposal of high-level radioactive wastes in geologic repositories. Code of Federal Regulations, Title 10, Part 60. Washington, DC: U.S. Government Printing Office.

Nuclear Regulatory Commission. 1992. Risk Assessment: A Survey of Characteristics, Applications, and Methods Used by Federal Agencies for Engineered Systems. Washington, DC: U.S. Nuclear Regulatory Commission.

Park, J.R., R.G. Baca, N.E. Eisenberg, R.W. Janetzke, and B. Sagar. 1994. IPA Phase 2 total system code and scenario analysis. Proceedings of the Fifth Annual International High-Level Radioactive Waste Conference. La Grange Park, IL: American Nuclear Society. 
Petrie, G.M., J.T. Zellmer, J.W. Lindberg, and M.G. Foley. 1982. Geologic Simulation for a Hypothetical Site in the Columbia Plateau, Volume 1. PNL-3542. Richland, WA: Pacific Northwest Laboratory.

Raiffa, H. 1968. Decision Analysis. Reading, MA: Addison Wesley.

Raimbault, P., C. Izabel, and J.M. Peres. 1992. Methodology developed by the French National Nuclear Waste Management Agency (ANDRA) for the performance assessment of a deep geological repository. Proceedings of the Third International Conference on High Level Radioactive Waste Management. La Grange Park, IL: American Nuclear Society: 510-516.

Ringrose, P.S., A.F. Chadwick, F.A.T. Kleissen, J.A.P. Larkin, D.T. Pollock, and R.D. Wilmot. 1990. Probabilistic simulation of the long-term evolution of radioactive waste disposal sites. Safety Assessment of Radioactive Waste Repositories. Paris, France: Nuclear Energy Agency: Organization for Economic Cooperation and Development: 427-436.

Ross, B. 1987. A first survey of disruption scenarios for a high-level waste repository at Yucca Mountain, Nevada. SAND85-7117. Albuquerque, NM: Sandia National Laboratories.

Sandia National Laboratories. 1992. Preliminary Comparison with 40 CFR Part 191, Subpart B for the Waste Isolation Pilot Plant, December 1991, 6 Volumes. SAND91-0893. Albuquerque, NM: Sandia National Laboratories.

Sandia National Laboratories. 1993. Preliminary Performance Assessment for the Waste Isolation Pilot Plant, December 1992, 6 Volumes. SAND92-0074. Albuquerque, NM: Sandia National Laboratories.

Stephens, M.E., and B.W. Goodwin. 1990. Scenario analysis for the postclosure assessment of the Canadian concept for nuclear fuel waste disposal. Proceedings of the Safety Assessment of Radioactive Waste Repositories. Paris, France: Nuclear Energy Agency: Organization for Economic Cooperation and Development: 405-416.

Sumerling, T.J. (ed). 1992. Dry Run 3: A Trial Assessment of Underground Disposal of Radioactive Wastes Based on Probabilistic Risk Analysis: Overview. DoE/HMIP/RR/92.039, London, England: UK Department of the Environment: Her Majesty's Inspectorate of Pollution.

Swedish Nuclear Power Inspectorate. 1991. SKI Project-90. SKI Technical Report 91:23. Stockholm, Sweden: Swedish Nuclear Power Inspectorate.

Thompson, B.G.J. 1988. A Method of Overcoming the Limitation of Conventional Scenario-Based Assessments by Using Monte Carlo Simulation of Possible Future Environmental Changes. PAAG/DOC/88/11. Paris, France: Nuclear Energy Agency: Organization for Economic Cooperation and Development.

Thompson, B.G.J. and B. Sagar. 1993. The development and application of integrated procedures for post-closure assessment, based on Monte Carlo simulation: the probabilistic systems assessment (PSA) approach. Reliability Engineering and System Safety 42: 125-160. 
U.S. Department of Energy. 1980a. Final Environmental Impact Statement, Waste Isolation Pilot Plant. Washington, DC: U.S. Department of Energy.

U.S. Department of Energy. 1980b. Waste Isolation Pilot Plant Safety Analysis Report. Carlsbad, NM: U.S. Department of Energy.

U.S. Department of Energy. 1988. Site Characterization Plan, Yucca Mountain Site, Nevada Research and Development Area, Nevada. DOE/RW-0199. Washington, DC: U.S. Department of Energy.

U.S. Environmental Protection Agency. 1985. Environmental standards for the management and disposal of spent nuclear fuel, high-level and transuranic radioactive wastes; final rule. Code of Federal Regulations, Title 40, Part 191. Washington, DC: U.S. Government Printing Office.

Woo, G. 1992. A Statistical Model of Future Human Actions. PM 1130/TR.8. London, England: Yard Ltd.

Zimmermann, D.A., E.J. Bonano, P.A. Davis, C.P. Harlan, and M.S.Y. Chu. 1992. Peer Review of the U.K. DoE Dry Run 3 Exercise (A Trial Probabilistic Risk Assessment of a Hypothetical Nuclear Waste Repository at Harwell, Oxfordshire). SAND92-1945. Albuquerque, NM: Sandia National Laboratories. 


\section{TITLE AND SUBTITLE}

Review of Scenario Selection Approaches for Performance Assessment of High-Level Waste Repositories and Related Issues

CNWRA 94-002

\begin{tabular}{|l|l|} 
& \\
\hline 5. AUTHOR(S) B.J. Bonano, * R.G. Baca &
\end{tabular}

3. DATE REPORT PUBLISHED

August 1995

FIN OR GRANT NUMBER B6666

6. TYPE OF REPORT
8. PERFORMING ORGANIZATION - NAME AND ADDRESS (If NRC, provide Division, Office or Region,
name and malling address) Southwest Research Institute Center for Nuclear Waste Regulatory Analyses 6220 Culebra Road San Antonio, TX 78228-0510
Beta Corporation International

6719 Academy, NE

Albuquerque, NM 87109

9. SPONSORING ORGANIZATION - NAME AND ADDRESS IIf NRC, tvpe "Same as above"; if contractor, provide NRC Division, Office or Region, U.S. Nuclear Regulatary Commission, and malling address.)

Division of Regulatory Applications

Office of Nuclear Regulatory Research

U.S. Nuclear Regulatory Commission

Washington, DC 20555-0001

10. SUPPLEMENTARY NOTES

11. ABSTRACT (200 words or less)

The selection of scenarios representing plausible realizations of the future conditions-with associated probabilities of occurrence-that can affect the long-term performance of a high-level radioactive waste (HLW) repository is the commonly used method for treating the uncertainty in the prediction of the future states of the system. This method, conventionally referred to as the "scenario approach," while common is not the only method to deal with this uncertainty; other methods, such as the environmental simulation approach (ESA), have also been proposed. Two of the difficulties with the scenario approach are the lack of uniqueness in the definition of the term "scenario" and the lack of uniqueness in the approach to formulate scenarios, which relies considerably on subjective judgments. Consequently, it is difficult to assure that a complete and unique set of scenarios can be defined for use in a performance assessment. Because scenarios are key to the determination of the long-term performance of the repository system, this lack of uniqueness can present a considerable challenge when attempting to reconcile the set of scenarios, and their level of detail, obtained using different approaches, particularly among proponents and regulators of a HLW repository.

\section{KEY WORDS/DESCR!PTORS (List words or phrases that will assist researchers in locating the report.)}

high-level radioactive waste, waste repository, scenario approach, environmental simulation approach (ESA), performance assessment, Oragnization of Economic Cooperation and Development

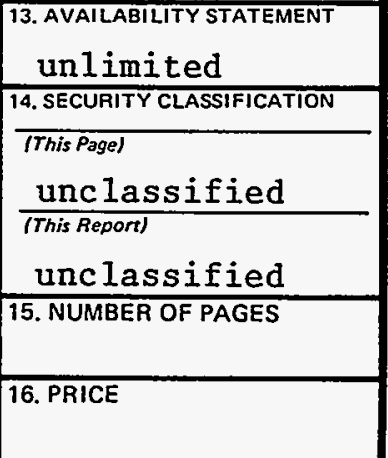

